\title{
Developing a Framework for Model Improvement of Building Thermal Performance under Urban Microclimate Interactions
}

\author{
Mohammadreza Shirzadia ${ }^{a}$ Mohammad Naghashzadegan ${ }^{\mathrm{a}, 1}$, Parham A. Mirzaei $^{\mathrm{b}}$ \\ a Mechanical Engineering Department, University of Guilan, Rasht, Iran \\ ${ }^{\mathrm{b}}$ Architecture and Built Environment Department, University of Nottingham, Nottingham, UK
}

\begin{abstract}
Accurate analysis of building thermal performance in urban areas, where sheltering effects of the surrounding buildings or other obstacles are very important, requires reliable and robust simulation tools. Building energy simulation (BES) tools and computational fluid dynamic (CFD) models are extensively used for analyzing the buildings thermal performance under the urban microclimate interactions. Nevertheless, the large uncertainty in the input parameters of BES tools and the inherent uncertainty in the values of the closure coefficients of Reynolds averaged Naiver-Stoke (RANS) turbulence models significantly restrict the reliability and accuracy of BES and CFD models in highly dense urban areas.
\end{abstract}

Thus, in this study a systematic framework for improving the reliability and accuracy of the BES and CFD models was proposed which consists of different statistical methods, a stochastic optimization approach, and model approximation techniques. In this framework, at first, the CFD model was calibrated through a closure coefficients optimization campaign in which experimental data were utilized to define different validation metrics as the objective functions in the optimization formulation. In the second step, the calibrated CFD model was utilized to conduct a series of CFD simulations for the real-geometry buildings in order to calibrate the BES model through proper definitions of the BES model's input parameters, such as adaptive discharge coefficient, local wind profile, and convective heat transfer coefficients (CHTCs) over the building façades.

The developed framework was applied to a small cross-ventilated office building which was surrounded by neighboring buildings in a neutral $A B L$ condition. Results showed noticeable deviations in prediction values by the default and calibrated BES models for crossing airflow rate, local velocity, surfacedaveraged wind pressure, CHTCs, and cooling load. Deviations up to $60 \%$ were found in the prediction values of the energy saving potential by the default and calibrated BES modes.

\footnotetext{
${ }^{1}$ Corresponding author: Rasht, Khalij Fars highway, Iran

Tel.: (+98) 013-33690274-8

Email: naghash@guilan.ac.ir
} 


\section{Introduction}

The increasing rate of population and urbanization, which expected to exceed over 9 billion by 2050 [2], will result in more mega cities with highly-packed urban areas. This can significantly reduce the urban ventilation which impacts the building energy consumption, outdoor air quality, pedestrians' health and comfort, as well as indoor air quality [3]. As a result, a great number of researchers have been focusing on the building thermal performance and its interactions with urban microclimate over the past 20 years.

Different methods proposed to study the building thermal performance under the urban microclimate interactions. On-site measurement have been used widely to study different aspects of urban microclimate interactions, including pressure distribution around buildings [4], outdoor thermal comfort [5, 6], urban heat island (UHI) [7-9], natural ventilation [10-13], and building energy audit [14]. However, the application of on-site measurement is limited due to the high cost of the experimental apparatus and the incapability to control the environmental parameters such as wind speed, wind direction, turbulence level, sheltering condition, etc. Wind tunnel measurement is also utilized for urban studies such as cross-ventilation [1, 15], airflow distribution around high-rise buildings [16], unstable atmospheric boundary layer $(A B L)$ around high-rise buildings [17], wind surface pressure over building facades [18, 19]. Again, such studies are limited due to the cost and time limitations in addition to the complex calibration procedures of measurement apparatus that directly affect the measurement quality.

Alternatively, building energy simulation (BES) tools, which are based on the assumption of fully-mixed air, are used frequently in most of the realistic engineering projects; however, the poor accuracy of BES tools in calculation of convection heat transfer, infiltration and exfiltration, and noticeable uncertainty in the input parameters to these models, result in inaccurate estimation of building thermal performance under the microclimate interactions where sheltering effects have to be considered. Numerical models based on the Computational fluid dynamics (CFD), as a modern and developing approach, can provide detailed information of the flow parameters in urban studies while they are generally cheaper than the on-site and wind tunnel measurements and more accurate than the BES models. Nonetheless, transient simulation by CFD models is very time demanding and cannot be used directly alongside BES models which have time steps ranging from seconds to years for hourly- and yearly-based calculations. 
As described in [20,21], BES and CFD models provide complementary information about the building performance; hence, an accurate prediction of building thermal and flow behavior cannot be achieved by separate application of BES and CFD [22]. This led to developing new approaches based on BES and CFD coupling which gain a very good popularity in the community in recent years. BES and CFD coupling approaches for prediction of building thermal performance under the microclimate interactions have been used frequently in different urban studies, including urban thermal environment $[23,24]$, town energy balance model [25, 26], building energy model [27-29], thermal load optimization [30], utilization of natural ventilation [12, 31-33], urban canopy model development [34, 35], urban heat island [36], and thermal comfort [37]. However, despite many researches on development of CFD and BES coupling applications in urban studies, the accuracy of BES and CFD models is still a challenging issue for calculation of the flow parameters in dense urban areas in cities [38].

On one hand, there is a noticeable uncertainty in the input parameters of the embedded models in BES tools, e.g. wind pressure coefficient [39, 40], discharge coefficient of the openings [41, 42], wind velocity profile [11], and convective heat transfer coefficient [43]. On the other hand, as demonstrated in [38, 44, 45], the accuracy of Reynolds averaged Naiver-Stoke (RANS) models significantly decrease when sheltered effects of the surrounding buildings are considered in packed urban areas. A total error of more than $70 \%$ was reported in calculation of the crossing airflow rate through a sheltered building located in a moderate urban area density of $C_{A}=0.25$ using steady RANS models [45]. The prediction accuracy of the steady RANS models show a noticeably drops for urban area density larger than 0.25 [38]. The poor accuracy of steady RANS turbulence models in dense urban areas is related to the values of the semi-empirical closure coefficients, which are mainly adapted from the fundamental and classical flow problems, e.g. homogenous decaying turbulence, free sheer flow, and fully developed channel flow $[46,47]$. Nonetheless, such flows have limited similarities with the airflow characteristics in the ABL. More complex CFD models such as large eddy simulation (LES) also show significant deficiencies in accurate predictions of flow parameters around the sheltered buildings in highly-dense urban areas [48].

It can be concluded that, for urban microclimate interaction studies in dense urban areas, application of BES-CFD coupling with their default settings could result in inaccurate and unreliable output responses. To develop an accurate model based on BES-CFD coupling approach, it is necessary to improve the prediction accuracy of BES and CFD models at first step, and then in the next step, a proper coupling algorithm, such as static or dynamic approaches, to be utilized. Thus, the aim of this study is to introduce a systematic framework to improve the accuracy and reliability of BES and CFD models for urban studies. The main concept of the proposed methodology is based on the integration of different experimental and numerical data to calibrate CFD 
and BES models using different statistical analyses such as design of computational experiments, stochastic optimization, and approximation models (meta-models). At the first step, available experimental data were used to define different validation metrics for quantities of interest (QOI). In the second step, by integrating proper sampling techniques, such as Latin Hypercube Sampling (LHS), with stochastic optimization method, proper values for the closure coefficients of the RANS model were found in a way that the highest agreement between the CFD and experimental data was achieved. Third step deals with calibrating the BES model using available experimental data and the calibrated CFD model, which was developed in the previous step. The BES model calibration was done through modification of the model inputs, such as pressure and discharge coefficients, wind profile, and convective heat transfer coefficients (CHTC). The effectiveness of the proposed methodology was investigated for a small office building placed in an urban area under the sheltering condition. The variation of the building's cooling load and energy saving due to the cross-ventilation were studied using the developed framework and results were compared with different scenarios of BES and CFD models with default settings. CFD model improvement was conducted for the standard $k-\varepsilon$ model through calibrating its closure coefficient while the BES model improvement was done by introducing an adaptive discharge coefficient for the openings and a calibrated convective heat transfer coefficient using the calibrated CFD model.

\section{METHODOLOGY}

\subsection{Systematic Procedure for CFD and BES Model Improvement}

The proposed methodology is based on the model accuracy improvement of the CFD model through calibration of the closure coefficients and then using the calibrated CFD model to improve the BES model's accuracy through its input parameters such as surface wind pressure, discharge coefficient, velocity profile, and CHTCs. Different data sets, including experimental and numerical data are integrated in an systematic approach using statistical analyses and stochastic optimization to calibrate the CFD and BES models for the defined problem.

A schematic of the proposed methodology for BES and CFD models improvement is shown in Figure 1. First step includes the problem definition and then performing experimental measurements for the defined problem. The experimental measurements may include an on-site measurement for the actual building or it may be conducted inside a wind tunnel for a scaled model which has similar physical concepts with the actual building. Numerical results of high-fidelity CFD simulations can also be used if experimental data are not available, but as explained before, they should be used with caution. 


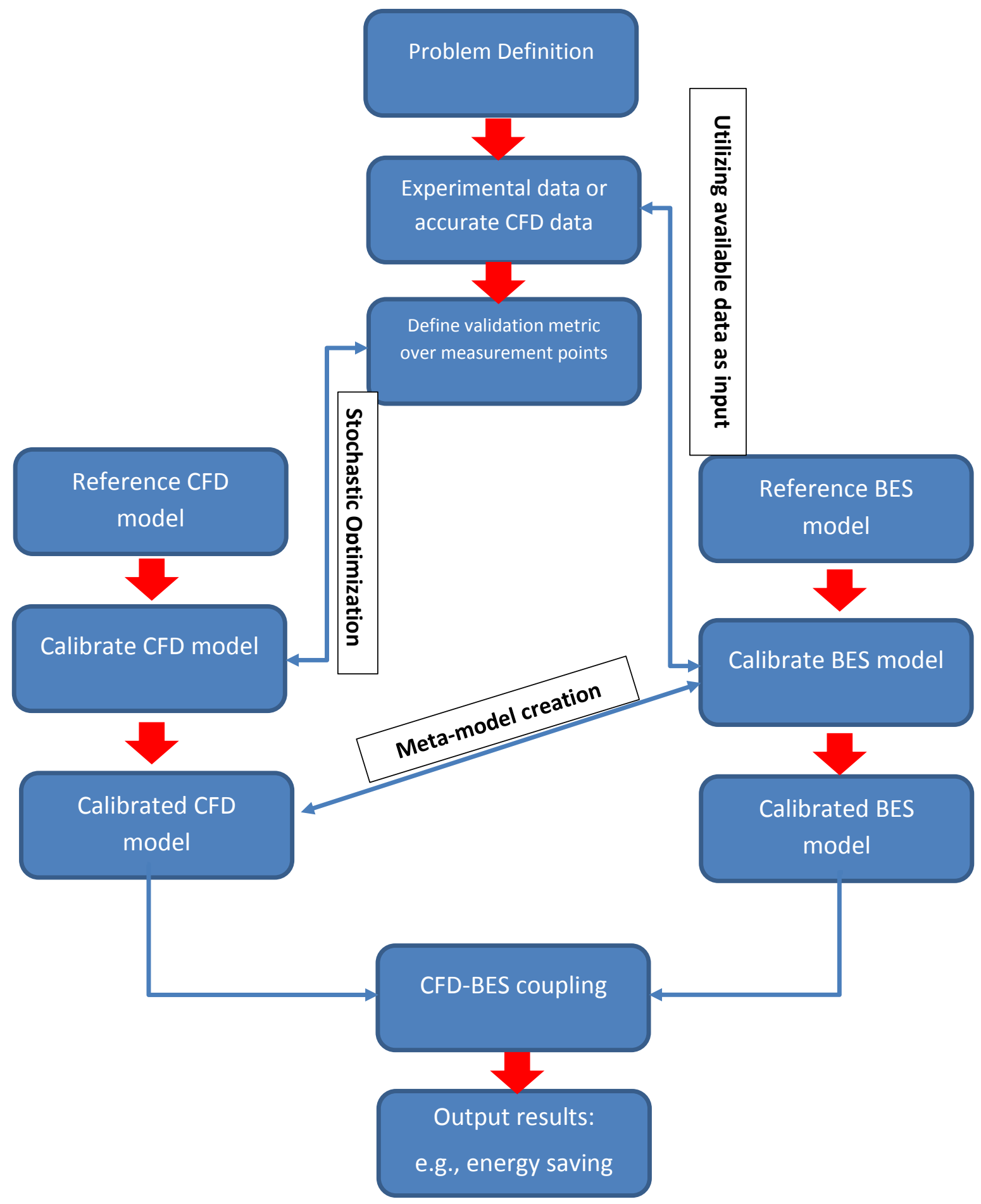

Figure 1 Schematic of the BES and CFD models calibration for urban microclimate interactions modeling

The measured experimental data or numerical data from the highly accurate numerical model are utilized to define validation metrics for the quantities of interest. Different validation metrics can be defined depending on the available information and objectives 
of the study. Most commonly used validation metrics in urban studies, according to [49], are the hit rate $q$, the fraction of the predictions within a factor of 2 of the observations $(F A C 2)$, the fractional bias $(F B)$, and the normalized mean square error (NMSE):

$$
\begin{aligned}
& q=\frac{1}{N} \sum_{i=1}^{N} n_{i} \quad \text { if }\left|\frac{P_{i}-Q_{i}}{P_{i}}\right| \leq D_{q} \text { or }\left|P_{i}-Q_{i}\right| \leq W_{q} \quad n_{i}=1 \text { else } n_{i}=0 \\
& F B=\frac{[Q]-[P]}{0.5([Q]+[P])} \\
& N M S E=\frac{\left[\left(Q_{i}-P_{i}\right)^{2}\right]}{[Q][P]} \\
& F A C 2=\frac{1}{N} \sum_{i=1}^{N} n_{i} \quad n_{i}=1 \quad \text { if } 0.5 \leq \frac{P_{i}}{Q_{i}} \leq 2 \text { else } n_{i}=0
\end{aligned}
$$

where $O_{i}$ and $P_{i}$ are the measured and computed values of a given variable for sample $i$, respectively. $N$ is the number of data points used in the calibration process. The ideal value of the validation metrics for a complete agreement between the experimental and numerical results is 1 for $q$ and $F A C 2$, and 0 for $F B$ and NMSE. These validation metrics are used directly for CFD model calibration.

\subsubsection{CFD model Calibration}

Second step of the proposed methodology for BES and CFD model improvement includes a systematic calibration procedure of the CFD model. In this step, the optimal values of the closure coefficients of the RANS turbulence model are found to achieve the best agreement between the experimental and numerical results in terms of the validation metrics defined in the previous step. Details of the RANS model calibration are given in $[45,47]$; hence, a brief description of the method is presented here.

A schematic of the RANS model calibration is shown in Figure 2. The calibration method is based on the integration of the Monte Carlo Sampling technique and stochastic optimization program which are coupled to a CFD solver. The input parameters of the calibration process are the probability distribution functions (PDF) of the closure coefficients of the RANS turbulence model. Different PDF forms can be considered for each closure coefficients $[50,51]$ which depend on the turbulence model and the epistemic range of the closure coefficients [52]. By coupling the Monte Carlo sampling technique and CFD model, input variables (closure coefficients) were randomly varied in accordance with their given PDFs. Then, the CFD model was repeatedly executed to characterize the statistical parameters of the output responses (i.e. validation metrics), including their mean and standard deviation values. In the next step, the PDFs of the output responses (validation metrics) were passed to a stochastic optimizer in which both mean value and standard deviation of the outputs were considered in the objective function. In the stochastic optimization process, not only can 
the best mean value of the desired outputs (validation metrics) be calculated, but it is also possible to minimize the standard deviation of the output values so as to reduce the effects of uncertainty of the input variables on the output responses.

The brief description of the formulation of stochastic optimization can be mathematically stated as finding a set of design variables $\mathrm{X}$ that [53]:

Minimize: $\quad f\left(\mu_{y}(X), \sigma_{y}(X)\right)$

Subject to: $\quad g_{i}\left(\mu_{y}(X), \sigma_{y}(X)\right) \leq 0$

$X_{L} \leq X \leq X_{U}$

where $X_{L}$ and $X_{U}$ are the lower and upper limits for input parameter $X$ and $g_{i}$ is the output constraint. A weighted sum approach was used to define the objective function, which includes a term for mean value of the output responses relative to the target and a term to minimize its standard deviation [53]:

$$
F=\sum_{i=1}^{l}\left[\frac{w_{1_{i}}}{s_{1_{i}}}\left(\mu_{y_{i}}-M_{i}\right)^{2}+\frac{w_{2_{i}}}{s_{2_{i}}} \sigma_{y_{i}}^{2}\right]
$$

where $w_{1_{i}}$ and $w_{2_{i}}$ are the weighting factors, and $s_{1_{i}}$ and $s_{2_{i}}$ are the scale factors for the mean and standard deviation terms. $M_{i}$ stands for the target of the output response $i$ and $l$ is the total number of output responses. The weighting factors determine the importance of each objective term while the scaling factors are used to normalize the objective terms. The calibrated CFD model was then utilized in the next step to calibrate the BES model.

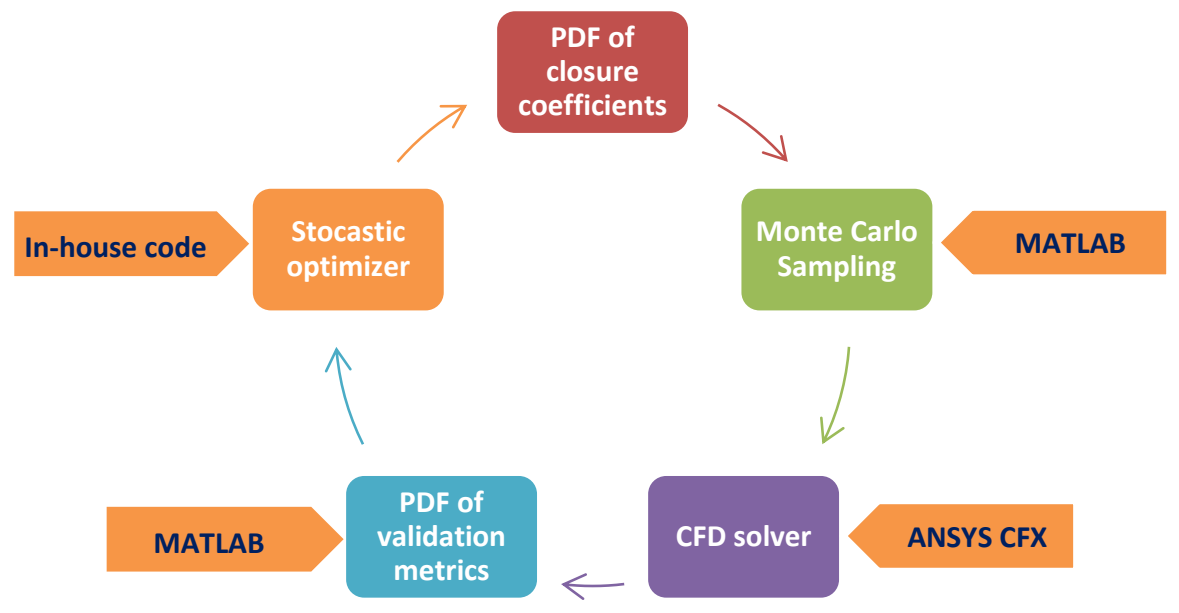

Figure 2 A schematic of CFD model calibration

\subsubsection{BES model Calibration}

The third step of the proposed methodology for BES and CFD models improvement is a systematic process of BES model calibration. The EnergyPlus simulation program was 
used in this study as BES tool. In this step, the calibrated CFD model from the previous step and available experimental data were used in a systematic manner to improve the accuracy of the BES model. Different parts of the BES model, including orifice-based model for cross-ventilation calculation, wind profile model, and CHTC correlations were calibrated. It is possible to develop a dynamic BES-CFD coupling and replace the BES estimations for airflow rate and $\mathrm{CHTCs}$ with airflow rate and surface temperature from calibrated CFD model. But, this type of data exchange is limited to only few CFD runs and it is not practical to exchange data between CFD and BES models for yearly-based calculations, because of the high computational costs of the CFD model. The alternative approach is to calibrate the orifice-based model, wind profile model, and CHTCs correlations through their input parameters using the proposed method in this study.

The procedure of the BES model calibration is shown in Figure 3. In the first step, adaptive Latin Hypercube sampling (LHS) method [54] was utilized to generate a proper number of computational experiments over the given design space. For parametric sensitivity study, it is also possible to use OFAT (one-factor-at-a-time) method [55] to generate samples by varying each input parameters independently over a specified level while holding other input parameters at their baseline point. Different design parameters, which depends on the targets of the study, can be defined, including geometrical parameters such as building dimensions $L, D, H$, openings' dimensions $L_{w}, W_{w}, H_{w}$ (see Figure $4(\mathrm{~b})$ ), morphological parameters such as urban area density $C_{A}$, weather data parameters such as wind speed $U_{z}$ and its direction $\theta$ and air temperature $T_{\text {air }}$. In the next step, a geometric model of the building and its surrounding environment was constructed using the ANSYS Design Modeler. Then the created model was passed into a mesh generator (ICEM CFD) in which a pre-defined mesh template was applied to the model in an automatic process. Generated mesh files were then transferred to a CFD solver (ANSYS CFX) in which pre-processing, processing, and post-processing were conducted automatically using predefined session files [56]. 


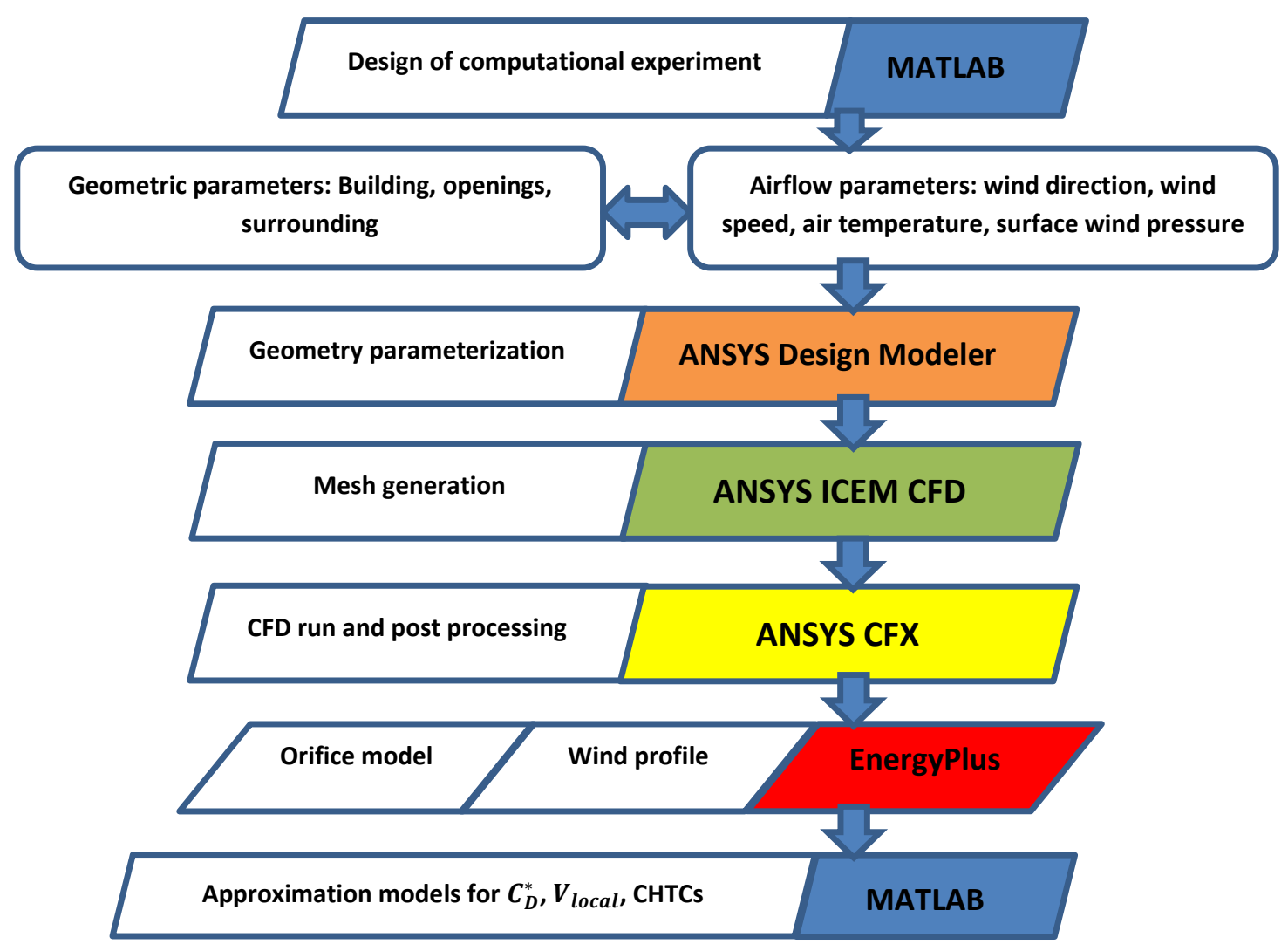

Figure 3 A schematic of BES model calibration for cross-ventilation and convective heat transfer coefficients

After the completion of the CFD simulations, the CFD prediction for airflow rate $\left(Q_{C F D}\right)$ and local wind velocity near the surfaces $\left(V_{\text {local }}\right)$ were then passed to the orifice-base model and the surface heat balance manager in the EnergyPlus model for calculation of the cross-ventilation and CHTCs over the external surfaces.

Using the calculated airflow rate by the calibrated CFD model and surface wind pressure coefficient from wind tunnel experiment [19], a new correlation for the discharge coefficient $\left(C_{d}^{*}\right)$ were obtained as a function of the building geometry, openings' dimensions and locations, wind direction and speed, and sheltering condition. The value of the modified discharge coefficient is assumed to be equal for the windward and leeward opening and is defined as follows:

$$
\begin{aligned}
& C_{d}^{*}= \frac{Q_{C F D}}{U_{r e f} A_{o 1} \sqrt{C_{P 1}^{E x p}-C_{P i}}} \\
& C_{P i}=\frac{C_{P 1}^{E x p}+\left(\frac{A_{o 2}}{A_{o 1}}\right)^{2} C_{P 2}^{E x p}}{1+\left(\frac{A_{o 2}}{A_{o 1}}\right)^{2}}
\end{aligned}
$$


where $Q_{C F D}$ is the airflow rate prediction by the calibrated CFD model while $U_{r e f}, A_{o 1}$, and $A_{o 2}$ are the free-stream velocity at a reference height and area of the windward and leeward openings, respectively. $C_{P 1}^{E x p}$ and $C_{P 2}^{E x p}$ are respectively the local-surface wind pressure coefficients at the windward and leeward openings obtained from the sealedbody measurement [19], and $C_{P i}$ is the internal pressure coefficient.

The accuracy improvement of three different $\mathrm{CHTC}$ models were investigated in this study, including ASHRAE task group model [57, 58], Model by Loveday and Taki [59], and Model by Liu and Harris [60]. However, only results of the model calibration of the Liu and Harris [60] model are presented for the considered test case. In these models, the local values of wind speed near the building surfaces are given based on empirical correlations. The predicted values by these correlations were replaced with the calibrated CFD model predictions to improve the model accuracy in a way similar the method presented in [28].

The ASHRAE task group model [57] is based on experimental measurements on a 6story building by Ito [58] in which local wind velocity was measured at $8 \mathrm{~m}$ from the roof and $0.3 \mathrm{~m}$ from the vertical surfaces. The proposed CHTC by ASHRAE task group is expressed as follows:

$h_{c}^{\text {ext }}=18.6\left(V_{\text {local }}\right)^{0.605}$

where local wind velocity $V_{\text {local }}$ is given by the following equations:

windward

$V_{\text {local }}=0.5 \frac{\mathrm{m}}{\mathrm{s}}$ if $V_{10}<2 \frac{\mathrm{m}}{\mathrm{s}}$ else $V_{\text {local }}=0.25 V_{10}$

leeward

$V_{\text {local }}=0.05 V_{10}+0.3 \frac{\mathrm{m}}{\mathrm{s}}$

where $V_{10}$ is the measured wind velocity at $10 \mathrm{~m}$ above the ground in the undistributed wind flow. The CHTC model presented by Loveday and Taki [59] is based on a fullscale measurement over an 8-stoty building. The values of local wind velocity were measured at a distance of $1 \mathrm{~m}$ from the façade. In this model, the following expressions are proposed for CHTC over the windward and leeward façades:

Windward:

$h_{c}^{\text {ext }}=16.15\left(V_{\text {local }}\right)^{0.397}$

Leeward

$h_{c}^{\text {ext }}=16.25\left(V_{\text {local }}\right)^{0.503}$

The relation between the local wind velocities near the facades and above the roof is given in below:

Windward

$V_{\text {local }}=0.2 V_{\text {roof }}-0.1$ if $-90<\varphi<-70$ or $70<\varphi<90$ 
$V_{\text {local }}=0.68 V_{\text {roof }}-0.5$ if $-70<\varphi<70$

Leeward

$V_{\text {local }}=0.15 V_{\text {roof }}-0.027$

where $\varphi$ stands for the wind angle. The third model, which is appropriate for low-rise buildings, is the model by Liu and Harris [60]. They conducted a full-scale experiment on the façade of a single-storey building in a partially sheltered condition. The values of the local velocities over the roof and near the façades were measured at $1 \mathrm{~m}$ above the roof and $0.5 \mathrm{~m}$ away from the walls, respectively. The values of CHTCs for windward and leeward façades are expressed in below equations:

Windward

$h_{c}^{\text {ext }}=6.31 V_{\text {local }}+3.22$

Leeward

$h_{c}^{\text {ext }}=5.03 V_{\text {local }}+3.19$

The relationships between the different wind speeds are expressed by the following equations:

Windward

$V_{\text {local }}=0.26 V_{10}+0.06$

Leeward

$V_{\text {local }}=0.19 V_{10}+0.14$

\subsubsection{Approximation Techniques}

In the final step, the calculated modified discharge coefficient $\left(C_{D}^{*}\right)$ and the local wind speed $\left(V_{\text {local }}\right)$ of each database sample were used to create an approximation model (meta-model) for $C_{D}^{*}$ and $V_{\text {local }}$. The outputs of the trained approximation models were then implemented in the EnergyPlus model as input parameters. In this study, radial basis function (RBF) model was used as a powerful approximation technique for highlynonlinear spaces. This model is a type of neural networks technique and is used for the interpolation in multiple-dimensional spaces. For given interpolation values $y_{1}, \ldots, y_{N}$ at data locations $x_{1}, \ldots, x_{N}$, the RBF model can be expressed as below [61, 62]:

$F(x)=\sum_{j=1}^{N} \alpha_{j} g_{j}(x)+\alpha_{N+1}$

where $g_{j}(x)$ is a set of radial basis functions, e.g. Cubic splines:

$g_{i}(x)=\left\|x-x_{j}\right\|^{3}$

The unknown coefficients $\alpha_{j}$ are obtained by solving a system of $N+1$ equations as follows: 
$\sum_{j=1}^{N} \alpha_{j} g_{j}(x)+\alpha_{N+1}=y_{i} \quad i=1, \ldots, N$

$\sum_{j=1}^{N} \alpha_{j}=0$

The accuracy of the RBF model is generally higher than the simple models such as response surface model (RSM); however, it requires considerably more samples for the training stage.

Once the trained approximation models for the adaptive discharge coefficient, wind velocity profile, and CHTCs were validated by using cross-validation method, they were passed into the EnergyPlus model to calculate desired building performance parameters. One of the most important outcomes of the building energy simulation tools is the evaluation of the saving energy potential of the natural ventilation, which is defined as below:

Energy saving $=\frac{Q_{\text {unventilated }}^{\text {cooling }}-Q_{\text {ventilated }}^{\text {cooling }}}{Q_{\text {unventilated }}^{\text {coling }}} \times 100$

where $Q_{\text {unventilated }}^{\text {cooling }}$ is the cooling load of the unventilated building (e.g. no crossventilation) and $Q_{\text {ventilated }}^{\text {cooling }}$ is the cooling load for the ventilated building which is utilizing the cross-ventilation for energy saving.

\subsection{BES model description}

The target building is a small single-story office building with the dimensions of $B \times D \times$ $H=4 m \times 6 m \times 3 m$, which is surrounded by 8 buildings with the same geometries (see Figure 4(a)). The target building is subjected to cross-ventilation through two openings on the windward and leeward façades with dimensions of $L \times W=1.77 \mathrm{~m} \times$ $0.68 \mathrm{~m}$, which is resulted in a window to wall ratio of $10 \%$. The thermo-physical properties of the building's construction materials are shown in Table 1.

Table 1 Thermo-physical properties of the building's construction materials

\begin{tabular}{|c|c|ccc|c|ccc|}
\hline & & \multicolumn{3}{|c|}{ Exterior walls } & Floor & \multicolumn{3}{c|}{ Roof } \\
\hline Property & Unit & Stucco & Brick & Plaster & Concrete & Slag & Felt & Concrete \\
\hline Thickness & $m$ & 0.025 & 0.101 & 0.019 & 0.203 & 0.012 & 0.009 & 0.05 \\
\hline Conductivity & $\frac{W}{m K}$ & 0.69 & 0.726 & 0.726 & 1.729 & 1.435 & 0.019 & 1.7295 \\
\hline Density & $\frac{k g}{m^{3}}$ & 1858.14 & 1922.21 & 1601.84 & 2242.58 & 881.01 & 1121.22 & 2242.58 \\
\hline Specific heat & $\frac{J}{\mathrm{kgK}}$ & 836.8 & 836.8 & 836.8 & 836.8 & 1673.6 & 1673.6 & 836.8 \\
\hline
\end{tabular}

The external glazed surfaces were assumed to be of double pane windows filled with air with a thermal resistance of $0.34 \frac{W^{2}}{K}$. The internal heat gains with 2 people were 
assumed to be $3500 \mathrm{~W}$ and $250 \mathrm{~W}$ for the electrical equipment and lightening, respectively. The building has one zone without any partitioning devise. Crossventilation calculations are performed using the Airflow Network (AFN) model embedded in the EnergyPlus simulation tool. The AFN model consists of two external node around the windward and leeward openings at a height of $1.5 \mathrm{~m}$ (see Figure 4(b)). The local wind pressure coefficients over the façades were obtained from wind tunnel experiments by [19] while the developed adaptive discharge coefficients $\left(C_{D}^{*}\right)$ were used in the AFN model. The positions of the local velocity measurement around the building surfaces are also depicted in Figure 4(b).

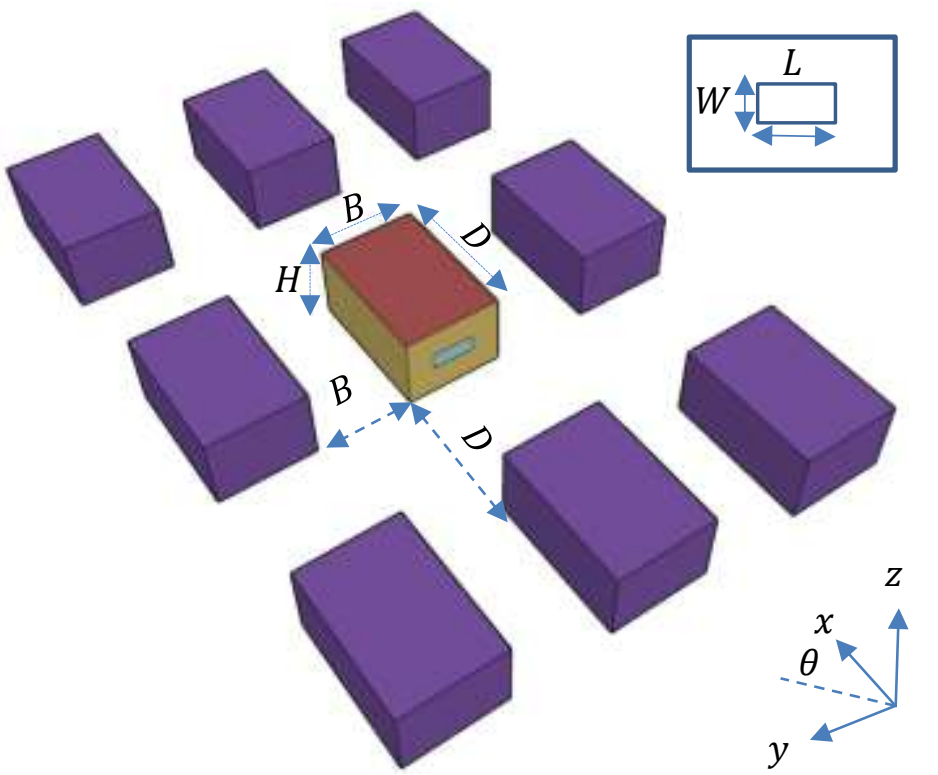

(a)

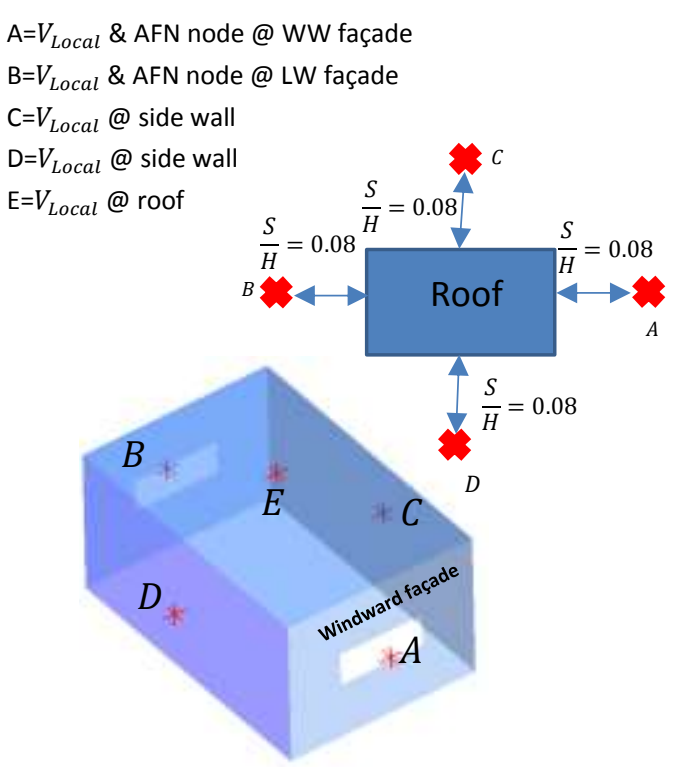

(b)

Figure 4 (a) Building geometry, (b) locations for local velocity measurment and AFN nodes

\subsection{CFD model description}

\subsubsection{Mathematical modeling}

The 3D steady Reynolds averaged Navier-Stokes (RANS) equations were used to simulate the airflow around the buildings. These equations can be derived by substituting mean and fluctuating components of the airflow variables into the NavierStokes equations [56]:

$$
\begin{aligned}
& \frac{\partial\left(\rho U_{j}\right)}{\partial x_{j}}=0 \\
& \frac{\partial}{\partial x_{j}}\left(\rho U_{i} U_{j}\right)=-\frac{\partial P}{\partial x_{i}}+\frac{\partial}{\partial x_{j}}\left(\tau_{i j}-\rho \overline{u_{\imath} u_{J}}\right)+S_{M_{i}}
\end{aligned}
$$

where $U_{i}$ is the average velocity and $u_{i}$ is the fluctuating velocity. $\tau_{i j}$ is the viscous stress tensor (including both normal and shear components of the stress tensor) and $S_{M_{i}}$ is the sum of body forces. Air was considered to be incompressible, which is 
reasonable for atmospheric boundary layer ( $A B L)$ flows [63]; the air density, specific heat capacity at constant pressure, and thermal expansion coefficient were considered to be $1.185 \mathrm{~kg} / \mathrm{m}^{3}, 1004.4 \mathrm{~J} / \mathrm{kg} \mathrm{K}$, and $0.0033561 / \mathrm{K}$.

In this study the $k-\varepsilon$ turbulence model with the Kato-Launder modification [64] was used, which is based on the eddy viscosity hypothesis. For the $k-\varepsilon$ model, values of $k$ and $\varepsilon$ come directly from their differential transport equations [65]:

$$
\begin{aligned}
& \frac{\partial \rho U_{j} k}{\partial x_{j}}=\frac{\partial}{\partial x_{j}}\left[\left(\mu+\frac{\mu_{t}}{\sigma_{k}}\right) \frac{\partial k}{\partial x_{j}}\right]+P_{k}-\rho \varepsilon \\
& \frac{\partial \rho U_{j} \varepsilon}{\partial x_{j}}=\frac{\partial}{\partial x_{j}}\left[\left(\mu+\frac{\mu_{t}}{\sigma_{\varepsilon}}\right) \frac{\partial \varepsilon}{\partial x_{j}}\right]+\frac{\varepsilon}{k}\left(C_{\varepsilon 1} P_{k}-C_{\varepsilon 2} \rho \varepsilon\right)
\end{aligned}
$$

where $P_{k}$ is the production of turbulence due to shear, which is modified by Kato and Launder [64]:

$P_{k}=\rho C_{\mu} \varepsilon S \Omega$

where $S$ and $\Omega$ are respectively the dimensionless strain and vorticity parameters, which are calculated as below:

$$
\begin{aligned}
& S=\frac{k}{\varepsilon} \sqrt{\frac{1}{2}\left(\frac{\partial U_{i}}{\partial x_{j}}+\frac{\partial U_{j}}{\partial x_{i}}\right)^{2}} \\
& \Omega=\frac{k}{\varepsilon} \sqrt{\frac{1}{2}\left(\frac{\partial U_{i}}{\partial x_{j}}-\frac{\partial U_{j}}{\partial x_{i}}\right)^{2}}
\end{aligned}
$$

Values of the closure coefficients, according to Launder and Spalding [66], are predefined as the default values for most of the popular CFD tools, such as ANSYS CFX, FLUENT, STAR CCM+, and PHOENIX, as below:

$C_{\mu}=0.09, C_{\varepsilon 1}=1.44, C_{\varepsilon 2}=1.92, \sigma_{k}=1, \sigma_{\varepsilon}=1.3$

\subsubsection{Solver settings}

The RANS equations were solved using the commercial software ANSYS CFX, which uses an element-based finite volume discretization method. The pressure-velocity coupling was based on the Rhie-Chow interpolation by Rhie and Chow [67] while a colocated grid layout was further implemented. The High Resolution Scheme was used for discretization of the advection terms while tri-linear shape functions were used to evaluate the spatial derivatives of the diffusion terms. For the near-wall treatment the 
scalable wall function method was utilized for the $k-\varepsilon$ model. The convergence criteria of $10^{-5}$ was set for the root mean square (RMS) residual of all variables.

\subsubsection{Computational domain, grid, and boundary conditions}

A cylindrical computational domain, as shown in Figure 5(a), was considered for the sheltered buildings based on the proposed methodology by Mirzaei and Carmeliet [68] and AIJ guidelines [69]. ICEM CFD meshing package was used to create structured hexahedral mesh applying the blocking technique.

A grid-sensitivity analysis was conducted for three different mesh numbers with $3,131,090,5,421,200$, and $9,393,520$ cells as coarse, medium and fine mesh configurations. Results showed a very negligible difference, less than $0.05 \%$, between the prediction of the velocity profile around the target building and surfaced-averaged wind pressure over the windward and leeward façades for the medium and fine meshes; hence, the medium mesh configuration was selected for the study.

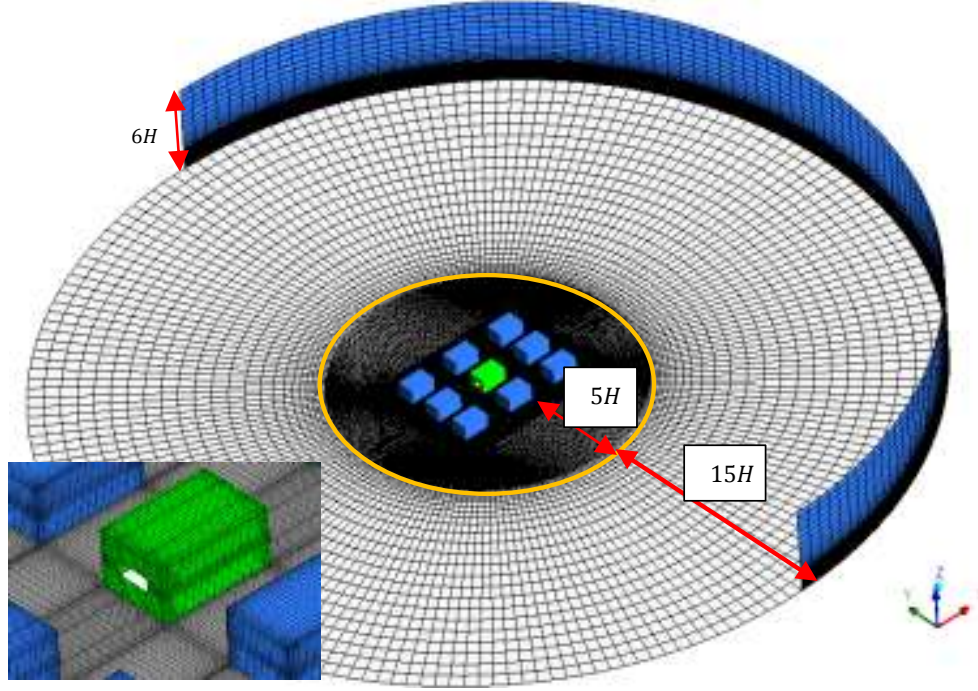

(a)
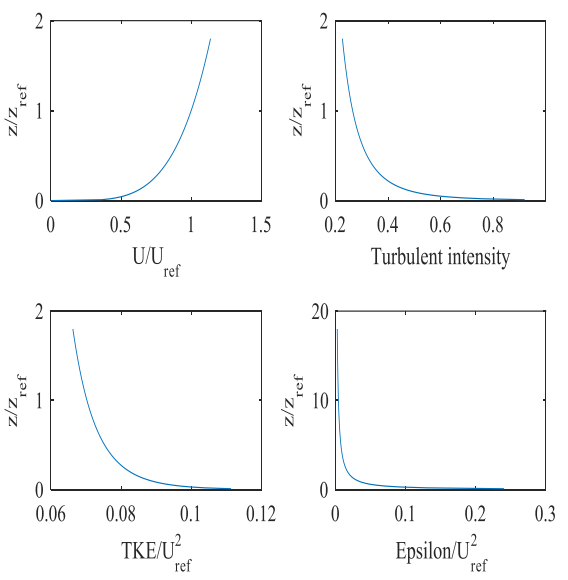

(b)

Figure 5 (a) Computational domain and grid arrangement. (b) Vertical distributions of streamwise velocity, turbulent intensity, turbulent kinetic energy, and its dissipation rate for the real building model at the inlet section.

Number of the cells around the building block was $35 \times 35 \times 55$ along its breath, depth, and height. An O-grid block with first-layer size of $0.01 \mathrm{~m}$ was used around the building, which was resulted to an average $Y^{+} \leq 200$ for the solid surfaces. No-slip boundary condition was considered for all solid walls. All solid walls were treated as smooth walls. Symmetric boundary condition was considered for the top boundary surface. Zero static pressure was applied at the outlet plane. Inlet boundary condition (see Figure 5(b)) for the streamwise velocity $U(z)$, turbulent kinetic energy (TKE) $k(z)$, and turbulent kinetic energy dissipation rate $\varepsilon(z)$ were implemented for a neutral atmospheric boundary layer using the recommendations in AIJ guideline [69]: 


$$
\frac{U(z)}{U_{H}}=\left(\frac{z}{H}\right)^{\alpha}
$$

where $U_{H}$ is the free-stream wind velocity at the reference height $H$ and $\alpha$ is the velocity profile exponent which is a function of terrain condition. The vertical profile of turbulent intensity $I(z)$ was estimated based on the proposed profile in [70]:

$I(z)=\frac{\sigma_{u}(z)}{U(z)}=0.1\left(\frac{z}{z_{g}}\right)^{(-\alpha-0.05)}$

where $\sigma_{u}(z)$ is the RMS value of velocity fluctuation in the streamwise direction while $z_{g}$ stands for the boundary layer thickness. In this study, an urban terrain with an exponent of $\alpha=0.22$ and a boundary layer thickness of $z_{g}=370 \mathrm{~m}$ was considered. The vertical profiles for TKE and $\varepsilon(z)$ were then calculated using the below equations:

$k(z)=(I(z) U(z))^{2}$

$\varepsilon(z)=C_{\mu}^{\frac{1}{2}} k(z) \frac{U_{H}}{H} \alpha\left(\frac{Z}{H}\right)^{\alpha-1}$

where $C_{\mu}$ denotes the model constant equals to 0.09 .

\section{Result and discussion}

\subsection{Results of the CFD model calibration}

The results of the experimental measurement by Tominaga and Blocken [1] were used for CFD calibration of the cross-ventilated building. The dimensions of the model building in the wind tunnel are close to the real building geometry with a scale of 1/25. The urban area density of the model and real buildings are equal to $C_{A}=0.25$. Details of the calibration process are presented in [45], hence a short description is provided here. The wind tunnel experiment was conducted to analyze the cross-ventilation of an unsheltered and sheltered building in an isothermal boundary layer wind tunnel. Target building (see Figure 6(a)) has a dimension of $B \times D \times H=0.2 \mathrm{~m} \times 0.2 \mathrm{~m} \times 0.16 \mathrm{~m}$ with two openings of the similar size $(0.092 \mathrm{~m} \times 0.036 \mathrm{~m})$ on opposite walls, which is resulted to a window to wall ration of $10 \%$ similar the real building model. Eight similar cuboid buildings without opening surrunded the target building at a distance equals to the building width $(D)$. Location of the measurement points in the central vertical section of the building is also displayed in Figure 6(a). Flow data at these measurement points, including velocity and TKE, were used for the calibration of the closure coefficients of the standard $k-\varepsilon$ model. 
For the CFD simulation of the scaled building model, a rectangular computational domain was considered. The rectangular domain was utilized because the wind tunnel measurements were conducted only for the normal wind angle. The domain width, length, and height were $2.6 \mathrm{~m} \times 4.2 \mathrm{~m} \times 0.96 \mathrm{~m}$. Boundary conditions were implemented at inlet boundary directly from the experiment, including the vertical profiles of the streamwise velocity and TKE (see Figure 6(b)). The default values and ranges of the closure coefficients for the calibration process are shown in Table 2. A total of 250 CFD simulations were executed during the calibration process. Simulations were conducted using an 8-core $\mathrm{AMD} \AA \mathrm{CPU}$ processor, which took about 4 days.

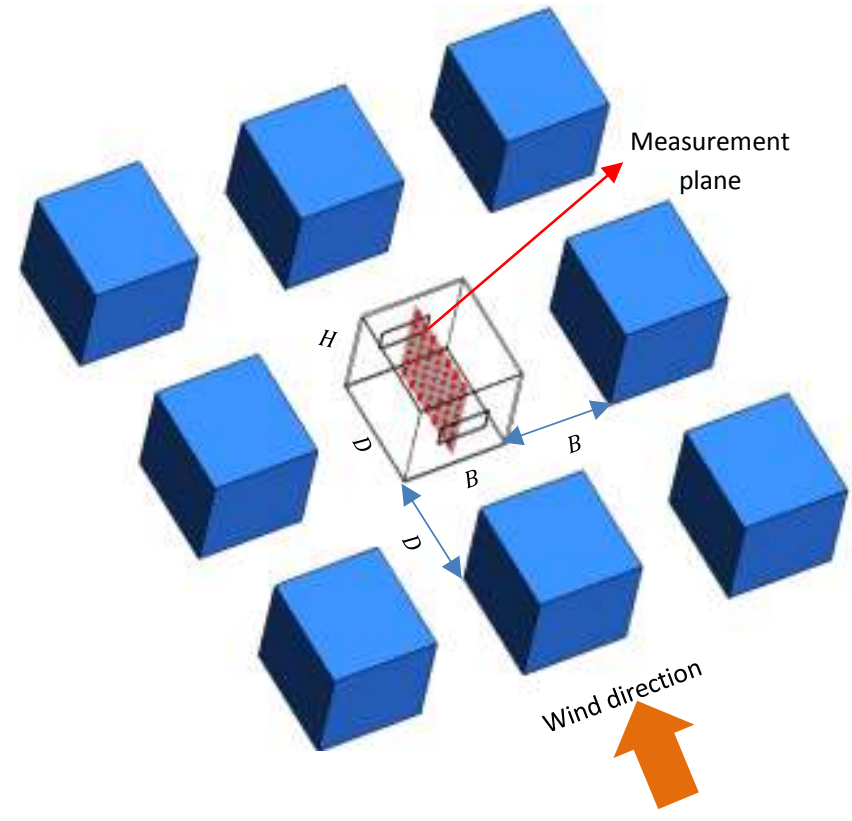

(a)
Dition

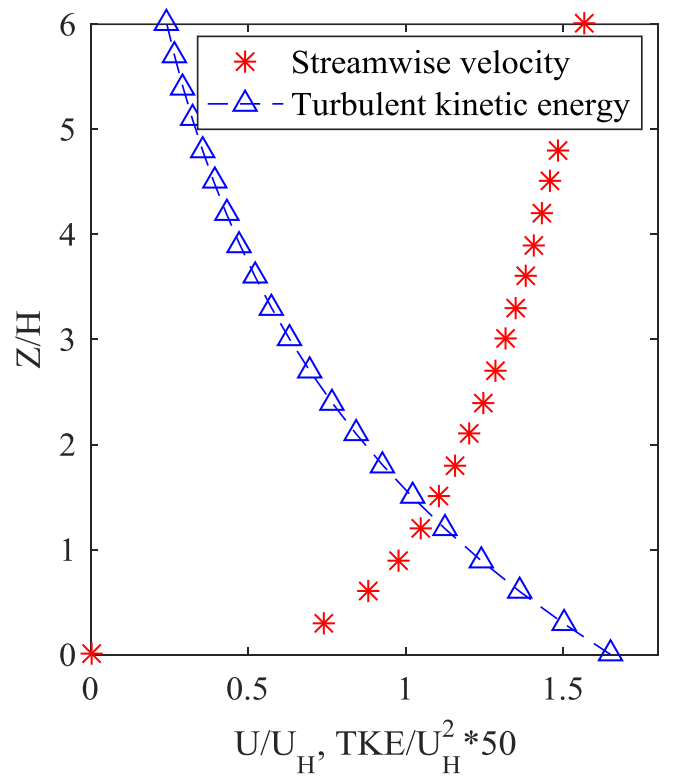

(b)

Figure 6 (a) Geometry of the mdel building and (b) the implemented boundary condition at the inlet section in the wind tunnel experiment

Table 2 Default value and range of the closure coefficients for the parametric sensitivity study

\begin{tabular}{ccccc} 
& $C_{\varepsilon 1}$ & $C_{\varepsilon 2}$ & $\sigma_{k}$ & $C_{\mu}$ \\
\hline & & & & \\
Standard value & 1.44 & 1.92 & 1.0 & 0.09 \\
Ranges & $1.0-1.5$ & $1.5-3.2$ & $0.8-1.4$ & $0.05-0.15$
\end{tabular}

Two validation metrics, including FAC2 and NMSE, were considered for the streamwise velocity and TKE at 63 measurement points in a vertical plane shown in Figure 6(a). As described in methodology section, both the mean and standard deviation values of the validation metrics were considered in the objective function. The maximum iteration for the optimization loop was set to 100 while a termination accuracy of $10^{-6}$ was considered for optimization convergence. The objective functions of FAC2 and NMSE were considered to be respectively maximized and minimized during the optimization 
process. An equal importance was considered for the mean and the standard deviation values of the validation metrics, hence a weighing factor of 1 was considered for $w_{1_{i}}$ and $w_{2_{i}}$ in equation(6). The values of the scaling factors $s_{1_{i}}$ and $s_{2_{i}}$ were set to 1 for all objectives in this equation.

The effectiveness of the optimization methodology can be discussed in terms of validation metrics as they were considered in the objective function definition. The predicted value of $F A C 2$ for the velocity field increased from 0.12 for the standard $k-\varepsilon$ model to 0.29 for the calibrated $k-\varepsilon$ model. The NMSE value for TKE field noticeably decreased from 49.4 for the standard $k-\varepsilon$ model with default closure coefficients to 9.8 for the calibrated $k-\varepsilon$ model with optimized closure coefficients. It is worthy to note that the obtained value for NMSE it is still far from the ideal value of 0 . As described in [45, 47], it is mainly due to the inherent incapability of RANS models to capture the unsteady contribution of the TKE inside the street canyons.

Both validation metrics for velocity and TKE, i.e. FAC2 and NMSE were insensitive to the variation of $\sigma_{k}$. The optimum values of the closure coefficients, resulted in the highest mean value for the validation metrics with the lowest standard deviation, were found as follows:

$C_{\varepsilon 1}=1.5, C_{\varepsilon 2}=3.2, C_{\mu}=0.141, \sigma_{\varepsilon}=0.294, \sigma_{k}=1$

The streamlines at the vertical center plane inside the building model and the vertical profiles of the streamwise velocity at three streamwise locations inside the building model $\left(\frac{x}{D}=0.125, \frac{x}{D}=0.5, \frac{x}{D}=0.875\right)$ are shown in Figure 7 for the $k-\varepsilon$ model with default and modified closure coefficients while they are compared with the experimental results. In the case of the default closure coefficients, the velocity field inside the building model is not accurately simulated mainly due to the poor prediction of the momentum diffusion and TKE inside the upstream and downstream cavities around the target building, and also incorrect pressure difference estimation across the openings of the target building [45]. For the case of the modified coefficients the CFD model shows a considerable improvement in predicting the velocity field inside the target building. In the case of the calibrated $k-\varepsilon$ model with the modified coefficients, the velocity gradient is modeled more accurately than the default coefficients results at the windward opening $\left(\frac{\mathrm{x}}{\mathrm{D}}=0.125\right)$. The streamwise velocity at the upper part of the building is under-predicted for both models which is related to the inaccuracy of models in predicting the TKE at that region. It is due to the inherent incapability of steady RANS in reproducing the transient contribution of TKE for highly-transient phenomena such as the flapping jet and Kelvin-Helmholz instability [1, 44, 45]. 

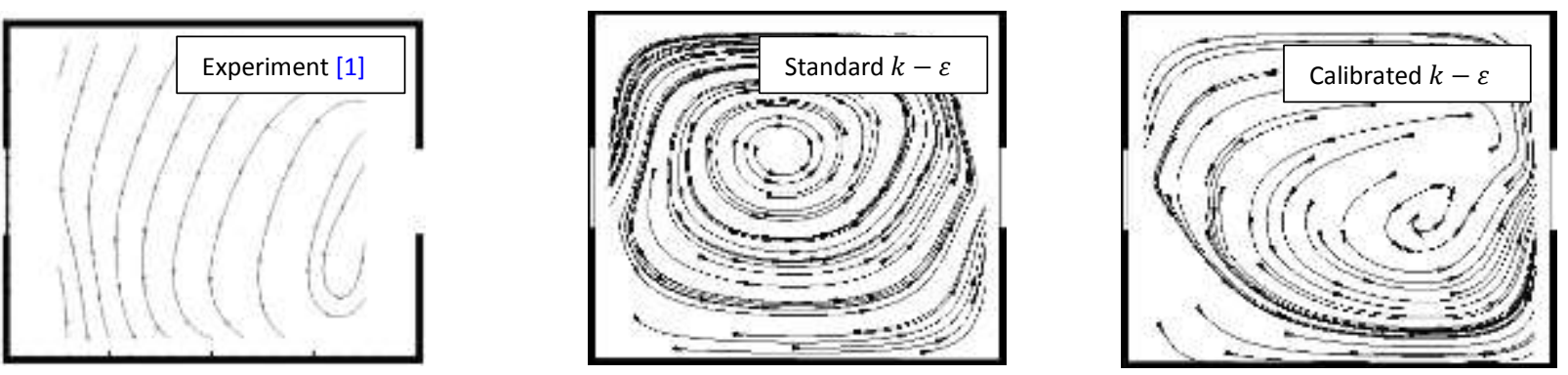

(a)

* Experiment — Standard k-e -.- k-e with modified coefficients

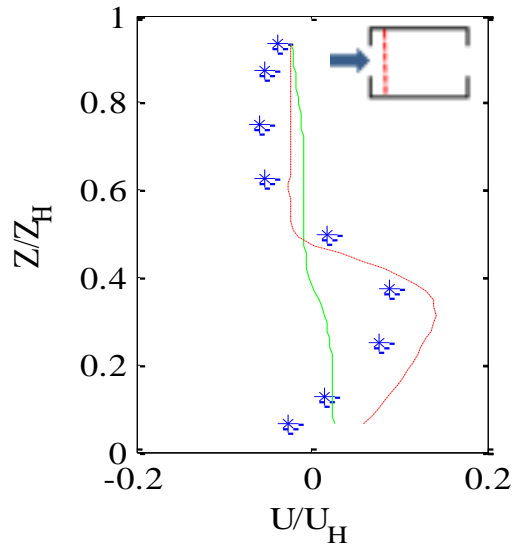

inlet plane $\left(\frac{\mathbf{x}}{\mathbf{D}}=\mathbf{0 . 1 2 5}\right)$

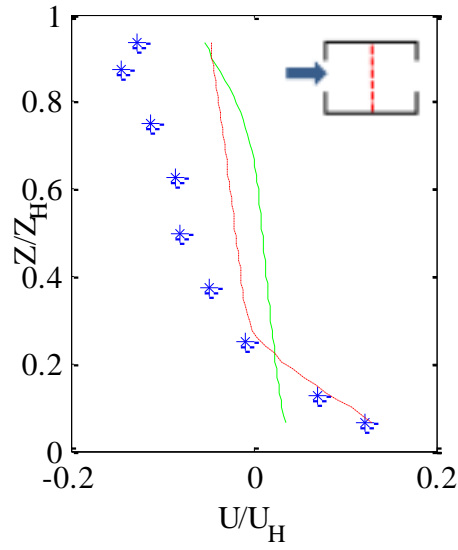

center plane $\left(\frac{\mathbf{x}}{\mathbf{D}}=\mathbf{0 . 5}\right)$

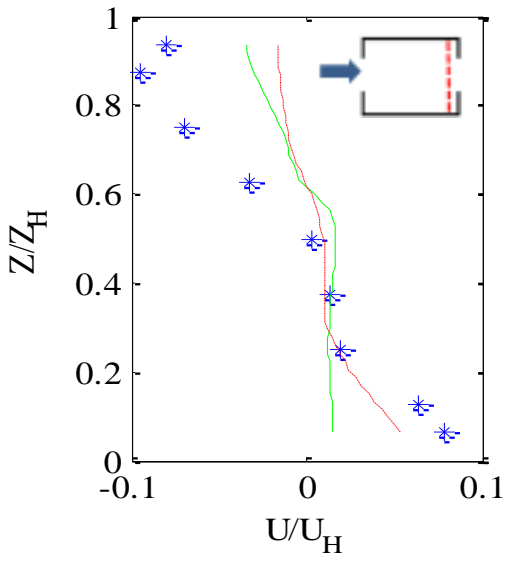

outlet plane $\left(\frac{\mathrm{x}}{\mathrm{D}}=\mathbf{0 . 8 7 5}\right)$

(b)

Figure 7 (a) Streamlines in the vertical center section of the building model. (b) Vertical distribution of the streamwise velocity inside the building at: $\frac{x}{D}=0.125, \frac{x}{D}=0.5$, and $\frac{x}{D}=0.875$

An airflow rate value of about 0.07 was measured by Tominaga and Blocken [1] by using the trace gas method while the airflow prediction by the standard $k-\varepsilon$ model was -0.0004 . For the case of the calibrated model with modified closure coefficients, the non-dimensional airflow rate was estimated to be about 0.064 , which is a quite closer number to the experimental result with an error than $8 \%$.

The calibrated $k-\varepsilon$ model was used for CFD modeling of the real geometry model to predict crossing airflow rate through the target building and estimate local velocity around it. In order to show the model improvement of the calibrated RANS model, in Figure 8(a), values of the surface-averaged wind pressure difference over the windward and leeward facades $\left(\Delta C_{P}=\right.$ $C_{P}^{\text {Windward }}-C_{P}^{\text {Leeward }}$ ) of the real building model is shown for different wind angles. Results are compared with experimental measurements for mean and extreme values conducted by Tamura [71]. The predicted values by the standard $k-\varepsilon$ model are out of the expected ranges reported in the experiment for wind angles less than $25^{\circ}$ and more than $60^{\circ}$. The calibrated $k-\varepsilon$ model shows a significant improvement in prediction of the surface wind pressure for all wind angles less than $70^{\circ}$. For wind angles larger than $70^{\circ}$ the predicted values by the calibrated CFD model are very close to the minimum extreme values reported in the experiment. This is due to the fact that the CFD calibration process was done only for normal 
wind angle. In Figure $8(\mathrm{~b})$, variation of the non-dimensional airflow rate $\left(\frac{Q}{A_{\text {facade }} U_{10}}\right)$ is depicted for the standard and calibrated $k-\varepsilon$ models. The deviation of two models in prediction of the airflow rate is more than $140 \%$ for normal wind angle. This deviation decreases at higher wind angles and reaches to a value about $4 \%$ for wind angle of $45^{\circ}$. There is a pick in the airflow prediction by the standard $k-\varepsilon$ model in wind angle of $80^{\circ}$ which is not predicted by the calibrated model.

The variation of the local velocity near the windward and leeward façades (see Figure $4(b)$ ) is shown for different wind angles in Figure 8(c). The difference between the local velocity predictions by the standard and calibrated $k-\varepsilon$ models is generally higher for the leeward façade than the windward façade. The highest deviation of the local velocity predictions for the windward and leeward façades are $75 \%$ and $330 \%$, respectively, which are observed at wind angles of $65^{\circ}$ and $85^{\circ}$. The variation of the local velocities near the roof and side walls showed the same trend, thus they are not shown here. The maximum deviations for the side wall and roof velocity predictions by the standard and calibrated $k-\varepsilon$ models were found to be about $11 \%$ and $160 \%$, respectively, which were occurred at wind angles of $10^{\circ}$ and $30^{\circ}$.

The calculated local velocities near the building walls were used in the CHTC model by [60] to estimate the CHTCs over the outer surfaces as shown in Figure 8(d). The trend is similar to the one estimated for the local velocity (see Figure 8(c)) with a maximum deviation of about $78 \%$ for wind angle of $65^{\circ}$ near the windward façade and a value of $124 \%$ for the leeward façade at $85^{\circ}$ wind angle. 


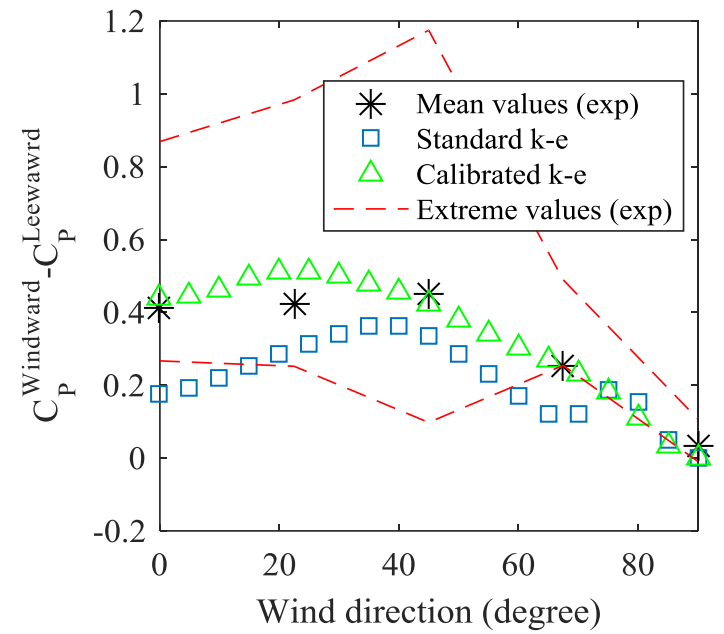

(a)

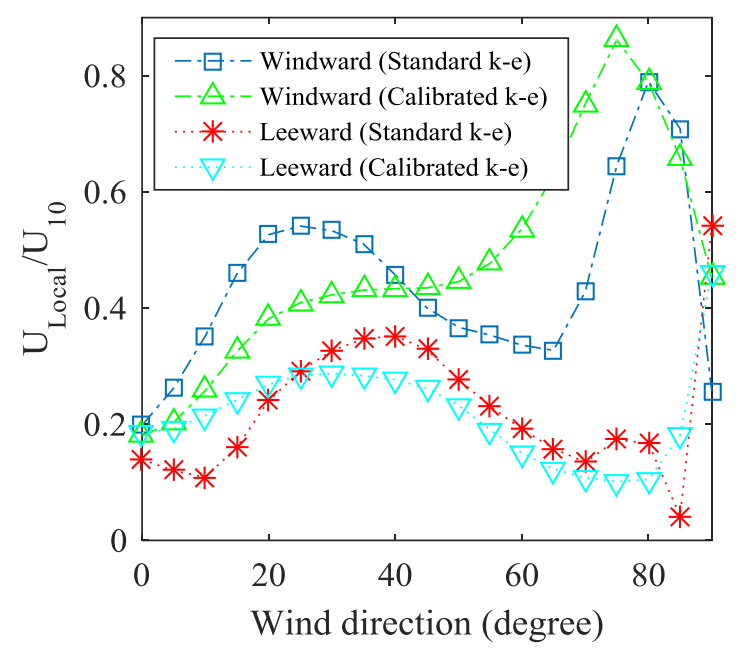

(c)

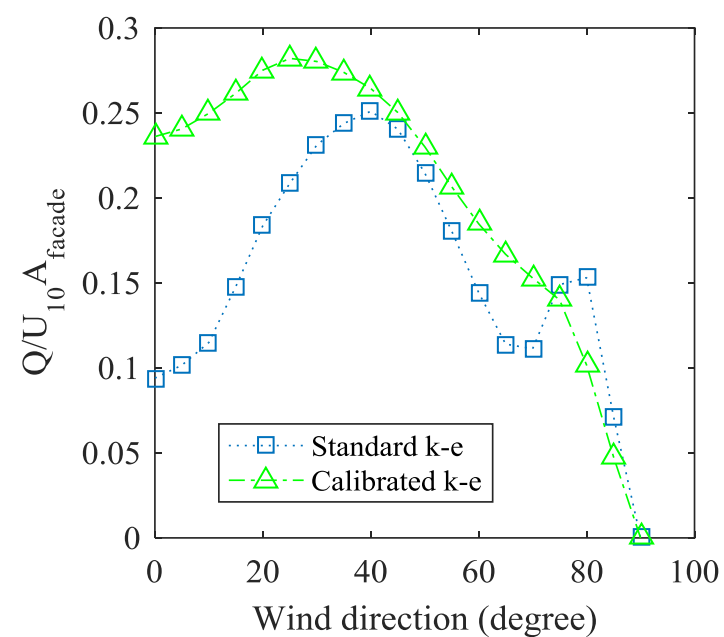

(b)

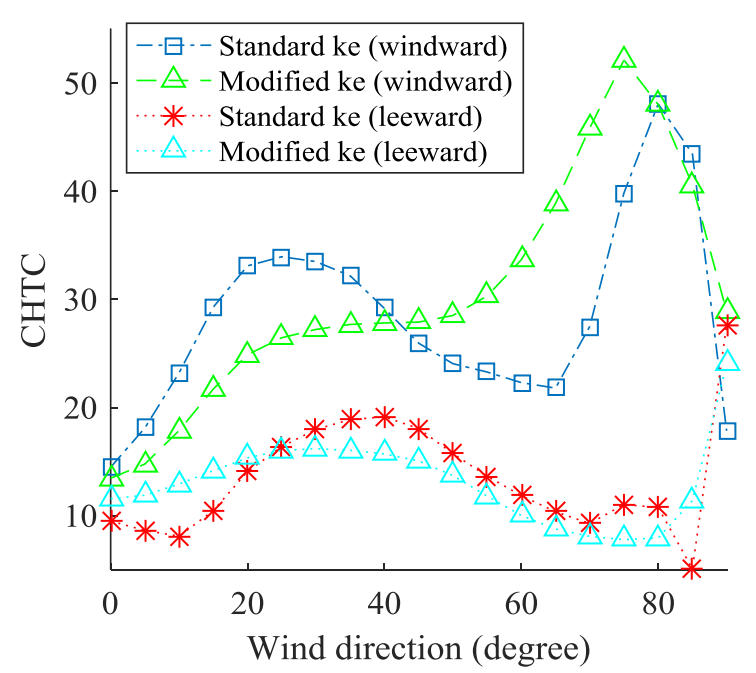

(d)

Figure 8 Variation of (a) the surface-averaged wind pressure difference, (b) non-dimensional airflow rate, (c) local velocity, and (d) CHTCs versus wind angle by the standard and modified $k-\varepsilon$ models for the small office building model

\subsection{BES model calibration results}

Results of the calibrated CFD model was used to calibrate the BES model of the office building through introducing an adaptive discharge coefficient $\left(C_{D}^{*}\right)$ and local velocity $\left(U_{\text {local }}\right)$ (see Figure 3 ) which are functions of urban area density and wind angle. The calculated values for the adaptive discharge coefficient were passed to the AFN model embedded in the EnergyPlus model while local velocities were used to define new CHTCs and replaced the default values in the EnergyPlus surface heat balance Manager Module. As depicted in Figure 9(a), a constant value of 0.7 is used for discharge coefficient as the default value in the AFN model. But, the effects of the surrounding building, opening position, and wind angle can be considered in the developed adaptive discharge coefficient. For the considered building geometry the $C_{D}^{*}$ rises from 0.67 to 0.8 when wind angle increases from $0^{\circ}$ to $20^{\circ}$, but it decreases 
uniformly to a value of 0.5 for wind angle of $65^{\circ}$. After a small pick around $75^{\circ}$, the $C_{D}^{*}$ decreases to 0 for wind angle of $90^{\circ}$. The variation of non-dimensional airflow rate $\left(\frac{Q}{A_{\text {facade }} U_{10}}\right)$ versus the wind angle is shown in Figure $9(\mathrm{~b})$ for default and calibrated EnergyPlus models. For the EnergyPlus model with default setting, a constant value of 0.7 was considered for the discharge coefficient while wind surface pressure over the façades were calculated using the embedded correlation in the AFN given by Swami and Chandra [72]. For the calibrated EnergyPlus model the adaptive discharge coefficient $\left(C_{D}^{*}\right)$ from the calibrated RANS model and wind surface pressure coefficients from [19] were passed into the AFN model for crossing airflow rate calculations. The estimated airflow rate by the default EnergyPlus model remains constant around a value of 0.32 for wind angles between $0^{\circ}$ and $60^{\circ}$, but it decreases dramatically for larger wind angles and hits a minimum of zero for wind angles of $90^{\circ}$. The prediction values by the calibrated model are pretty lower than the default model, which is due to the sheltering effects of the surrounding buildings that are considered in the calibrated model in contrast to the default model where no sheltering effects were included. For normal wind angle, the predicted values for the airflow rate are 0.32 and 0.24 for the default and calibrated models, respectively, which result to a deviation of about $25 \%$ between the two models. The highest deviation between the airflow rate predictions by the default and calibrated models is found at $60^{\circ}$ wind angles which is about $45 \%$. 


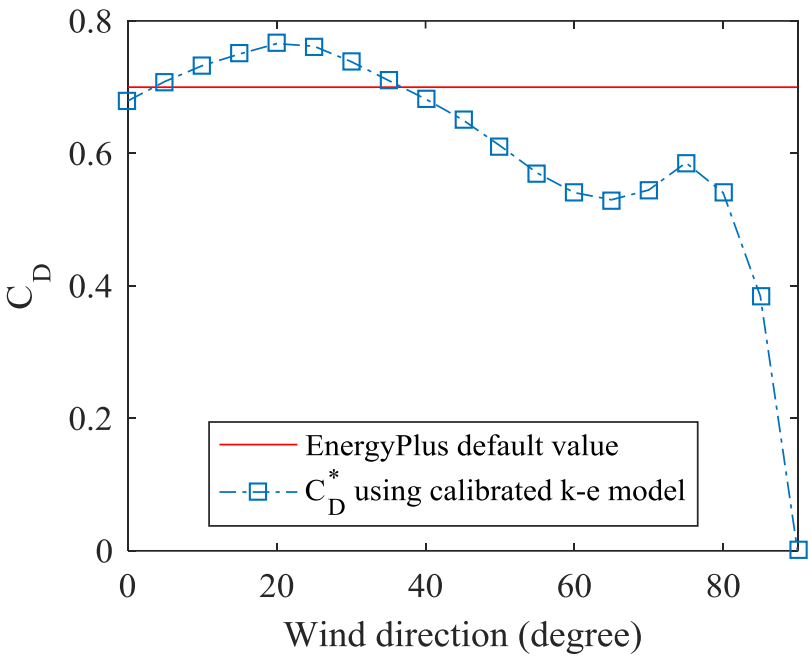

(a)

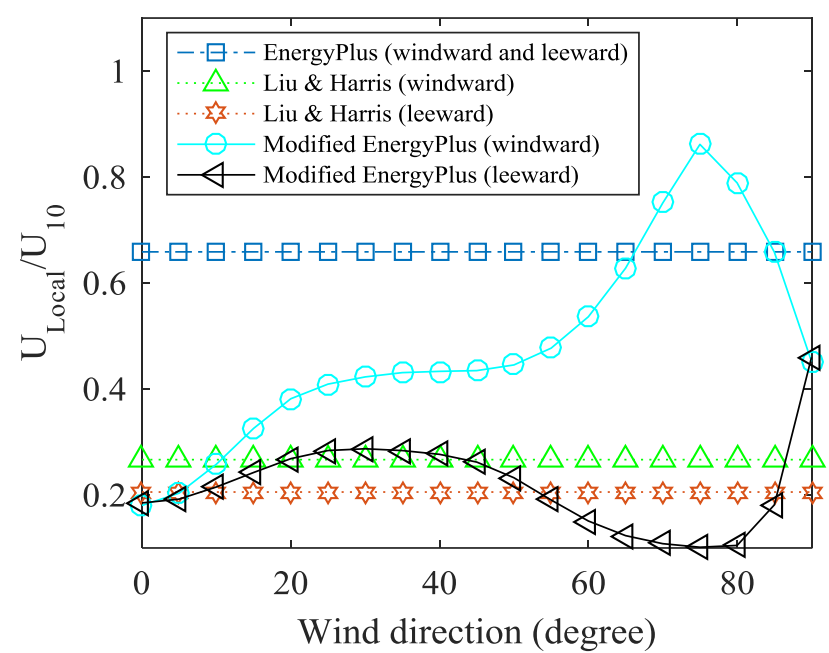

(c) Y-range to be cheked

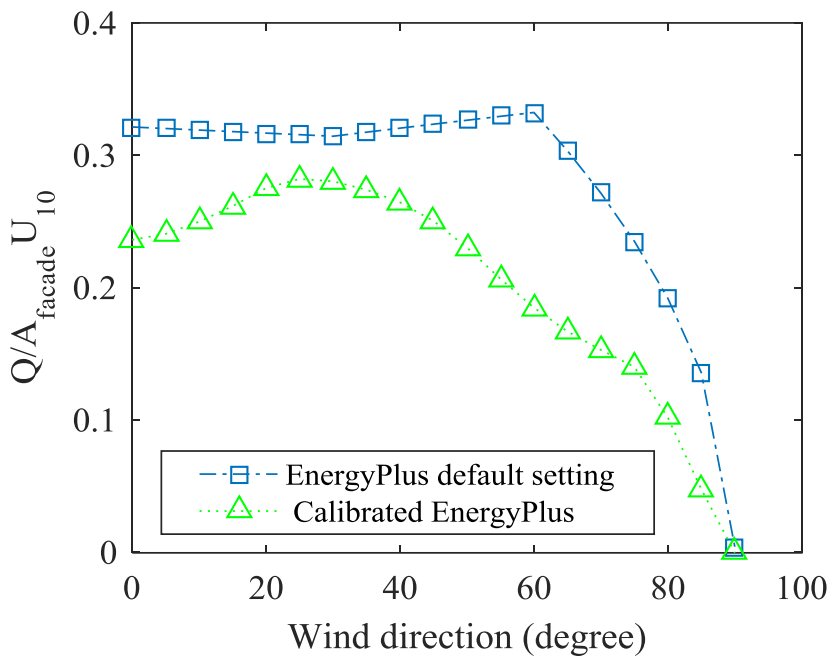

(b)

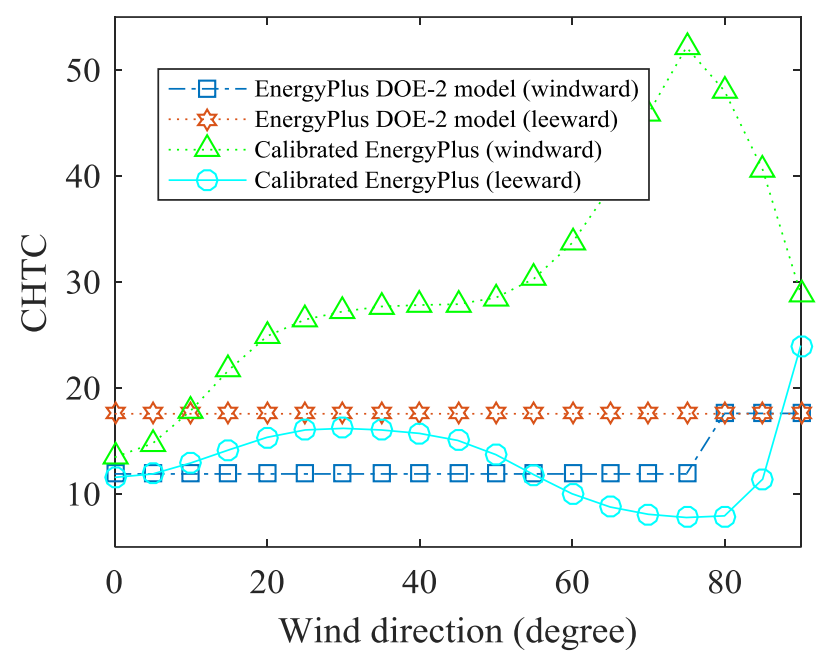

(d)

Figure 9 Variation of (a) the opening's discharge coefficient, (b) non-dimensional airflow rate, (c) local velocity, and (d) CHTCs over the windward and leeward façades for the small-office building by the default and calibrated EnergyPlus models

In Figure $9(\mathrm{c})$, the local velocity $\left(\frac{U_{\text {Local }}}{U_{10}}\right)$ near the windward and windward façades are shown as a function of wind angle for default and calibrated EnergyPlus models and the model proposed by Liu and Harris [60]. In the default EnrgyPlus model, the local velocity is a function of the reference velocity at the metrological weather station $\left(U_{10}\right)$ and the terrain type; hence its value doesn't vary with wind angle. The predicted value by the default EnergyPlus model is $\frac{U_{\text {Local }}}{U_{10}}=0.65$ which is equal for the windward and leeward façades. The predicted values of local velocity by Liu and Harris [60] over the windward and leeward façades do not change with wind angle and are respectively $\frac{U_{\text {Local }}}{U_{10}}=0.26$ and $\frac{U_{\text {Local }}}{U_{10}}=0.21$. These values are significantly lower than the predictions by the default EnergyPlus model which is due to the sheltering effect by the trees and 
nearby buildings in the experimental measurement by Liu and Harris [60]. The local velocity predictions by the calibrated EnergyPlus model are close to the estimated values by the Liu and Harris [60] model for wind angles lower than $20^{\circ}$. For the modified EnergyPlus model, the local velocity over the windward façade increases slowly from $\frac{U_{\text {Local }}}{U_{10}}=0.18$ at $0^{\circ}$ wind angel to $\frac{U_{\text {Local }}}{U_{10}}=0.44$ at $50^{\circ}$ wind angle. Then, it rises rapidly and hits a maximum value of $\frac{U_{\text {Local }}}{U_{10}}=0.86$ at $75^{\circ}$ wind angle. The estimated local velocity over the leeward façade is less sensitive to the wind angle variation and it change from $\frac{U_{\text {Local }}}{U_{10}}=0.18$ to $\frac{U_{\text {Local }}}{U_{10}}=0.23$ for wind angles between $0^{\circ}$ and $50^{\circ}$. It declines to a minimum value of $\frac{U_{L o c a l}}{U_{10}}=0.1$ at wind angle of $80^{\circ}$, then surges to $\frac{U_{\text {Local }}}{U_{10}}=0.45$ at wind angle of $90^{\circ}$, which is exactly equal the local velocity over the windward façade at this wind angle. The difference between the local velocities near the windward and leeward façades reaches to its maximum value at wind angle of $75^{\circ}$.

The CHTC variation against the wind angle is depicted in Figure 9(d), where results of the default Energyplus model based on the DOE-2 correlation are compared with the results of the calibrated EnergtPlus model which is based on the modified correlation by Liu and Harris [60]. The CHTC prediction for the windward façade obtained by the default EnergyPlus model is about 11.89 for wind angles between $0^{\circ}$ and $75^{\circ}$, but it surges to a value of 17.60 for larger wind angles. The $\mathrm{CHTC}$ prediction by the default EnergyPlus for the leeward façade is about 17.56 and it remains constant for all wind angles. In the calibrated EnergyPlus model, the effects of the sheltering condition were included in the CHTC correlation, through the local velocity definition. The value of the calibrated EnergyPlus model prediction for the windward façade's CHTC increases uniformly from 13.45 to 54.15 when wind angle increases from $0^{\circ}$ to $75^{\circ}$. Then, it decreases rapidly to a value of 28.8 for $90^{\circ}$ wind angle. The predicted values for the leeward façade are lower than the windward façade, which is directly related to the higher velocity distribution around the windward façade in comparison with the leeward façade. The CHTC of the leeward façade increases from a value of 11.51 at $0^{0}$ to 16.03 at $35^{\circ}$ wind angle where the prediction is very close to the results of the default EnergyPlus model. The highest CHTC is predicted at $90^{\circ}$ which hits a value of 24.01 .

The deviations in the airflow rate and $\mathrm{CHTC}$ estimations by the default and calibrated EnergyPlus models resulted in noticeable difference between the cooling energy and energy saving estimations for the cross-ventilated building. This will be discussed in the next part in more details. 


\subsection{Cooling energy and energy saving potential for the cross- ventilated office building}

In Figure 10, variation of the maximum cooling load of the small office building is plotted against the wind angle using the default and calibrated EnergyPlus models. For the default EnergyPlus model a constant discharge coefficient value equals to 0.7 was considered for cross-ventilation calculations in the AFN model while the DOE-2 model was utilized for CHTC estimations of the outer walls. In the calibrated model, the adaptive discharge coefficient $C_{D}^{*}$ alongside the modified $\mathrm{CHTC}$ correlation by Liu and Harris [60] was used. The predicted maximum cooling load by the default EnergyPlus model is significantly lower than the one predicted by the calibrated model. For the default EnergyPlus model, a maximum cooling load of $11.4 \times 10^{5} \mathrm{~J}$ is estimated at normal wind angle while this value remains almost constant for larger wing angles up to $60^{\circ}$. The maximum cooling load of the building model then uniformly rises and hits a value of $48.3 \times 10^{5}$ at $90^{\circ}$ wind angle. The relatively small variation of the maximum cooling load for wind angles between $0^{\circ}$ and $60^{\circ}$ is related to the very low variation of the crossing-airflow rate calculated by the default EnergyPlus model in this wind angle range (see Figure $9(\mathrm{~b})$ ). At higher wind angles than $60^{\circ}$, the crossing airflow rate through the building decreases rapidly (see Figure $9(b)$ ), which results in a noticeable increase in the value of the cooling load. At wind angle of $90^{\circ}$, the crossing airflow rate is at its minimum, thus the highest cooling load is estimated in this wind angle to maintain the internal temperature at its defined set point. The estimated maximum cooling load by the calibrated model at normal wind angle is $21.2 \times 10^{5} \mathrm{~J}$, which is $85 \%$ larger the cooling load estimation by the default EnergyPlus model. This is due to airflow reduction caused by the sheltering effects of the surrounding buildings, which is not considered in the default EnergyPlus model. The value of the maximum cooling load by the calibrated model decreases slightly at $20^{\circ}$ but after that it surges uniformly and hit a maximum value of $48.9 \times 10^{5} \mathrm{~J}$ for wind angle of $90^{\circ}$. The highest deviation between the default and calibrated EnergyPlus models is observed at wind angle of $60^{\circ}$ with a value of $230 \%$. The deviation between the two models decreases for higher wind angles because of the reduction of the crossing airflow rate which consequently reduces the effect of the cross-ventilation on cooling load demand reduction. 


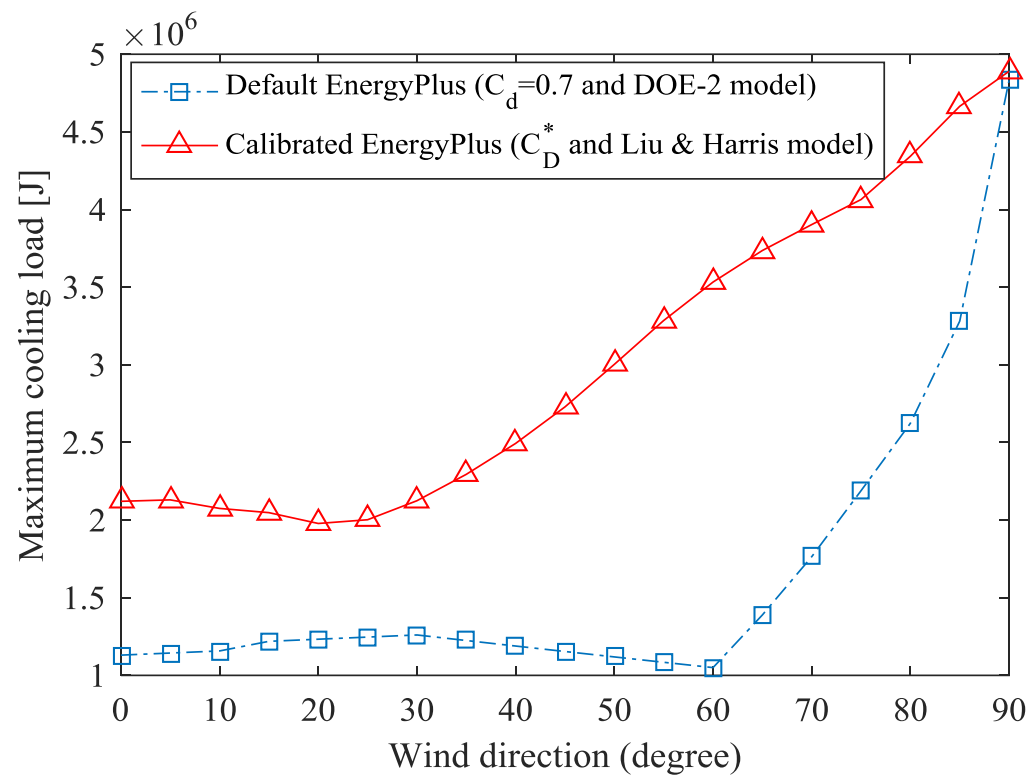

Figure 10 Maximum cooling load of the office building as a function of the wind angle by the default and calibrated EnergyPlus models

In Table 3, the energy saving potential (see equation (19)) due to the cross-ventilation is shown for different cases to demonstrate the effectiveness of the proposed calibration method for accurate estimation of the thermal performance of a cross-ventilated building under the microclimate interactions. Five different cases are considered, including Case_1, in which the default EnergyPlus model was used with $C_{P}$ from [72] (AFN default), constant $C_{D}=0.7$ for all wind angles, and DOE-2 model for CHTC calculations over the outside surfaces, Case_2 which is similar to Case_1 but TARP correlation is used for CHTC calculations, Case_3 which is again similar to Case_1 but CHTCs were calculated using the original model by Liu and Harris [60], Case_4, in which the calibrated BES model is used with adaptive discharge coefficient and modified CHTCs calculated by the standard $k-\varepsilon$ model with default closure coefficient, and Case_5, in which the calibrated EnergyPlus model was used with adaptive discharge coefficients and modified CHTCs from the calibrated $k-\varepsilon$ model.

The predicted energy saving for Case_1, i.e. default EnergyPlus model with DOE-2 model, remains constant at a value of about $77 \%$ when wind angle rises from $0^{0}$ to $65^{\circ}$. After that, the energy saving of the cross ventilation dramatically drops and reaches a minimum value of about $0 \%$ for wind angle of $90^{\circ}$. At wind angle of $90^{\circ}$, the crossing airflow rate is near zero; hence, the energy saving potential of the crossventilation reaches to zero. The trend of the energy saving obtained for case_2, which is based on default EnergyPlus settings and TARP model, is very similar with the Case_1's trend, but lower values for the energy saving is predicted for this model. The energy saving prediction for Case_2 is about $70 \%$ for wind angles in the range of $0^{0}$ and $65^{\circ}$. The difference between the Case_1 and Case_2 is due to the different 
CHTCs over the outside surfaces, which results in different convective heat fluxes across the façades.

Table 3 Energy saving variation of the cross-ventilation versus wind angle for the small office building

\begin{tabular}{|r|c|c|c|c|c|}
\hline wind angle & $\begin{array}{c}\text { Case_1 } \\
\text { Default EP \& AFN } \\
C_{D}=0.7, \\
\text { CHTC } \rightarrow \text { DOE-2 }\end{array}$ & $\begin{array}{c}\text { Case_2 } \\
\text { Default EP \& AFN } \\
C_{D}=0.7, \\
\text { CHTC } \rightarrow \text { TARP }\end{array}$ & $\begin{array}{c}\text { Case_3 } \\
\text { Default EP \& AFN } \\
C_{D}=0.7, \\
\text { CHTC } \rightarrow \text { Liu \& Harris }\end{array}$ & $\begin{array}{c}\text { Case_4 } \\
\text { Calibrated EP \& AFN } \\
C_{D}^{*} \& \text { CHTCs from } \\
\text { Standard } k-\varepsilon\end{array}$ & $\begin{array}{c}\text { Case_5 } \\
\text { Calibrated EP \& AFN } \\
C_{D}^{*} \& \text { CHTCs from } \\
\text { Calibrated } k-\varepsilon\end{array}$ \\
\hline 0.0 & 77.4 & 70.3 & 78.4 & 23.7 & 57.5 \\
\hline 5.0 & 77.1 & 70.0 & 78.2 & 24.9 & 57.2 \\
\hline 10.0 & 76.8 & 69.8 & 77.9 & 27.5 & 58.0 \\
\hline 15.0 & 75.8 & 68.9 & 76.9 & 34.0 & 58.6 \\
\hline 20.0 & 75.6 & 68.7 & 76.6 & 40.9 & 59.8 \\
\hline 25.0 & 75.3 & 68.4 & 76.3 & 44.7 & 59.2 \\
\hline 30.0 & 75.0 & 68.2 & 76.1 & 47.5 & 56.7 \\
\hline 35.0 & 75.7 & 68.8 & 76.8 & 48.0 & 53.2 \\
\hline 40.0 & 76.4 & 69.4 & 77.5 & 47.1 & 49.2 \\
\hline 45.0 & 77.1 & 70.1 & 78.2 & 42.8 & 44.4 \\
\hline 50.0 & 77.8 & 70.7 & 78.9 & 36.3 & 38.8 \\
\hline 55.0 & 78.5 & 71.3 & 79.6 & 29.0 & 33.0 \\
\hline 60.0 & 79.2 & 71.9 & 80.3 & 22.0 & 27.7 \\
\hline 65.0 & 72.5 & 65.8 & 73.5 & 15.8 & 23.3 \\
\hline 70.0 & 65.1 & 59.1 & 65.9 & 13.7 & 19.6 \\
\hline 75.0 & 56.6 & 51.4 & 57.4 & 16.5 & 16.0 \\
\hline 80.0 & 47.3 & 42.9 & 47.3 & 15.0 & 10.4 \\
\hline 85.0 & 34.1 & 30.9 & 34.1 & 7.7 & 4.0 \\
\hline 90.0 & 0.5 & 0.5 & 0.2 & 0.2 & 0.0 \\
\hline
\end{tabular}

For Case_3, in which default EnergyPlus model with original CHTCs by Liu and Harris [60] is used, the trend of the energy saving versus wind angle is very similar to the Case_1 which is based on default EnergyPlus settings and DOE-2 model. The values of CHTCs for the windward and leeward façades are very close for DOE-2 and Liu and Harris model; hence a very close energy saving is predicted by these two models.

In Case_4, in which the EneryPlus model was calibrated using the standard $k-\varepsilon$ model, lower energy saving are predicted for all wind angles than Cases 1, 2, and 3. The energy saving estimation rises from $23.7 \%$ to $48 \%$ for wind angles between $0^{0}$ and $35^{\circ}$. Then, it decreases to a value of $13.7 \%$ at $70^{\circ}$ wind angle. After a small pick at $75^{\circ}$ wind angle, the energy saving decreases uniformly to 0 at $90^{\circ}$ wind angle. When the calibrated $k-\varepsilon$ model was utilized to calibrate the EnergyPlus model, i.e. Case_5, the values of the energy saving changed significantly in comparison with the prediction values in the Case_4, in which the standard $k-\varepsilon$ model was utilized for BES model calibration. For wind angle of $0^{\circ}$, an energy saving of about $57.5 \%$ is predicted by the 
calibrated model which is about $34 \%$ larger than the prediction by Case_4. Energy saving remains nearly constant up for wind angles up to $25^{\circ}$, but it drops uniformly as the wing angle elevates. At wind angle of $45^{\circ}$, the calculated energy saving is about $49.2 \%$ which is very close to the predicted value in Caes_4.

The highest deviation between the energy saving predictions by the default EnergyPlus model (Case_1) and the calibrated EnergyPlus model (Case_5) is about $51 \%$ which is seen for wind angles between $60^{\circ}$ and $65^{\circ}$. At these wind angles, the deviation between the models predictions for airflow rate (see Figure 9(b)), local velocity (see Figure 9(c)), and CHTCs (see Figure 9(d)) are significantly large, hence different cooling energy was obtained by the default and calibrated models (see Figure 10) which was resulted in such a high deviation in the energy saving predictions. These results show that the application of BES tools and RANS CFD models with default settings could result in significant error in estimation of the flow properties distribution inside and outside a building and miscalculation of building thermal performance under the microclimate interactions in urban areas.

\section{4- Conclusion}

A framework for model improvement of the building thermal performance under the urban microclimate interactions was proposed which is based on the calibration of the BES and CFD models. In the proposed framework, different experimental and numerical data were integrated in order to calibrate the BES and CFD models using statistical methods, stochastic optimization, and model approximation techniques. For CFD model calibration, proper validation metrics from experimental measurement were defined and then were passed to a stochastic optimization process where the PDF of the closure coefficients of the RANS turbulence model were treated as random (uncertain) variables. The stochastic optimization was coupled to a Latin Hypercube Sampling model to generate and optimize the statistical variation of the validation metrics in a way that the best agreement between the numerical and experimental data was achieved. The calibrated closure coefficients were used to conduct a series of CFD simulations for the real-geometry building model. Results of the calibrated CFD model, including wind velocity near the façades, the crossing airflow rate through the openings, and experimental data from a wind tunnel campaign for surface wind pressure were then passed into a BES model. An approximation model based on RBF models was utilized to define a series of modified input parameters for the BES model, including adaptive discharge coefficient, modified CHTCs correlations, and local surface wind pressure coefficients over the building façades. The calibrated BES model was then used to calculate thermal performance of the building under the urban microclimate interactions. The proposed framework was applied for analyzing the thermal performance of a small cross-ventilated office building which was surrounded by 8 buildings in a regular 
arrangement with an urban area density of 0.25 . Two different experimental measurements from literature, including a wind tunnel measurement of a sheltered cross-ventilated building mode and a wind tunnel experiment over sealed-body models, were used for CFD and BES calibrations. Results showed that application of BES models with default settings and CFD models with default closure coefficients could result in unreliable outputs and miscalculate important parameters such as cooling load and energy saving potential of cross-ventilation for sheltered buildings in urban areas. The following finding can be addressed as the main conclusion of this study:

- Despite the fast growing application of BES and CFD coupling methods for urban studies, the accuracy of the models still need more consideration and definitely proper model improvement is necessary for building thermal performance calculation in dense urban areas.

- Application of steady RANS models with default closure coefficients for airflow analysis around the buildings in dense urban areas should be done with more caution, because the default closure coefficients were obtained based on classical flows and empirical models which are not appropriate for $A B L$ flow over the buildings in urban areas.

- The prediction accuracy of the calibrated RANS model showed significant improvement in calculation of the crossing airflow rate and surface wind pressure over the windward and leeward facades of a sheltered building.

- For the considered small office, the deviation between the airflow predictions by the standard and calibrated $k-\varepsilon$ models is a function of the wind angle and hits a maximum value of $45 \%$ at $60^{\circ}$ wind angle.

- The deviation of the standard and modified $k-\varepsilon$ models in prediction of the air velocity near the windward and windward façades changed with wind angle which was resulted in different $\mathrm{CHTC}$ with up to $60 \%$ difference.

- The EnergyPlus and AFN models with default settings miscalculated the crossing airflow rate, surface wind pressure coefficients, façades velocity and CHTC with a maximum deviation up to $330 \%$ relative to the results of the calibrated CFD model.

- The highest deviation in prediction of the building's maximum cooling load by the default and calibrated EnergyPlus models was found at wind angle of $60^{\circ}$ with a value of $230 \%$.

- Calculation of the energy saving potential of cross-ventilation by default EnergyPlus resulted in very different values in comparison with the results obtained by the calibrated model with a maximum deviation of about $51 \%$.

It is worthy to note that, the utilized wind tunnel experiments for calibration of the CFD model was conducted for normal wind angle, hence to achieve a more precise CFD calibration process further wind tunnel measurements are required to measure the airflow properties inside and outside the buildings at different wind angles. Future works 
will be focused to extent the proposed methodology for other wind angles than the normal one and also to consider the sheltering effects for different urban area densities than 0.25 .

\section{Acknowledgement}

The authors would like to express their gratitude to the University of Guilan for their financial support.

\section{References}

[1] Y. Tominaga, B. Blocken, Wind tunnel experiments on cross-ventilation flow of a generic building with contaminant dispersion in unsheltered and sheltered conditions, Building and Environment, 92 (2015) 452-461.

[2] O.E. Outlook, OECD Environmental Outlook to 2050: The Consequences of Inaction, in, Paris, France: OECD, 2012.

[3] F. Haghighat, P.A. Mirzaei, Impact of non-uniform urban surface temperature on pollution dispersion in urban areas, in: Building Simulation, Springer, 2011, pp. 227-244.

[4] P. Richards, R. Hoxey, Pressures on a cubic building-Part 1: Full-scale results, Journal of Wind Engineering and Industrial Aerodynamics, 102 (2012) 72-86.

[5] Y. Shimazaki, A. Yoshida, R. Suzuki, T. Kawabata, D. Imai, S. Kinoshita, Application of human thermal load into unsteady condition for improvement of outdoor thermal comfort, Building and Environment, 46 (8) (2011) 1716-1724.

[6] C.L. Tan, N.H. Wong, S.K. Jusuf, Outdoor mean radiant temperature estimation in the tropical urban environment, Building and Environment, 64 (2013) 118-129.

[7] Y. Hirano, T. Fujita, Evaluation of the impact of the urban heat island on residential and commercial energy consumption in Tokyo, Energy, 37 (1) (2012) 371-383.

[8] Y. Kawamoto, Effect of Urbanization on the Urban Heat Island in Fukuoka-Kitakyushu Metropolitan Area, Japan, Procedia Engineering, 169 (2016) 224-231.

[9] E. Krüger, R. Emmanuel, Accounting for atmospheric stability conditions in urban heat island studies: The case of Glasgow, UK, Landscape and Urban Planning, 117 (2013) 112-121.

[10] D.-S. Lee, S.-J. Kim, Y.-H. Cho, J.-H. Jo, Experimental study for wind pressure loss rate through exterior venetian blind in cross ventilation, Energy and Buildings, 107 (2015) 123-130.

[11] J. Lim, R. Ooka, H. Kikumoto, Effect of diurnal variation in wind velocity profiles on ventilation performance estimates, Energy and Buildings, 130 (2016) 397-407.

[12] A. Mochida, H. Yoshino, S. Miyauchi, T. Mitamura, Total analysis of cooling effects of crossventilation affected by microclimate around a building, Solar Energy, 80 (4) (2006) 371-382.

[13] J.S. Park, Long-term field measurement on effects of wind speed and directional fluctuation on wind-driven cross ventilation in a mock-up building, Building and Environment, 62 (2013) 1-8.

[14] Y. Ham, M. Golparvar-Fard, EPAR: Energy Performance Augmented Reality models for identification of building energy performance deviations between actual measurements and simulation results, Energy and Buildings, 63 (2013) 15-28.

[15] F. Peng, M.S. Wong, Y. Wan, J.E. Nichol, Modeling of urban wind ventilation using high resolution airborne LiDAR data, Computers, Environment and Urban Systems, 64 (2017) 81-90.

[16] Y. Tominaga, Flow around a high-rise building using steady and unsteady RANS CFD: Effect of largescale fluctuations on the velocity statistics, Journal of Wind Engineering and Industrial Aerodynamics, 142 (2015) 93-103. 
[17] R. Yoshie, G. Jiang, T. Shirasawa, J. Chung, CFD simulations of gas dispersion around high-rise building in non-isothermal boundary layer, Journal of Wind Engineering and Industrial Aerodynamics, 99 (4) (2011) 279-288.

[18] Y. Quan, Y. Tamura, M. Matsui, Mean wind pressure coefficients on surfaces of gable-roofed lowrise buildings, Advances in Structural Engineering, 10 (3) (2007) 259-271.

[19] Y. Quan, Y. Tamura, M. Matsui, S. Cao, A. Yoshida, S. Xu, Interference effect of a surrounding building group on wind loads on flat roof of low-rise building: Part I, Distribution of local wind pressure coefficient, Wind Engineers, JAWE, 32 (2007) 211-212.

[20] Z. Zhai, Q.Y. Chen, Numerical determination and treatment of convective heat transfer coefficient in the coupled building energy and CFD simulation, Building and Environment, 39 (8) (2004) 1001-1009.

[21] Z.J. Zhai, Q.Y. Chen, Sensitivity analysis and application guides for integrated building energy and CFD simulation, Energy and buildings, 38 (9) (2006) 1060-1068.

[22] Z. Zhai, Q. Chen, P. Haves, J.H. Klems, On approaches to couple energy simulation and computational fluid dynamics programs, Building and Environment, 37 (8) (2002) 857-864.

[23] H. Huang, R. Ooka, S. Kato, Urban thermal environment measurements and numerical simulation for an actual complex urban area covering a large district heating and cooling system in summer, Atmospheric Environment, 39 (34) (2005) 6362-6375.

[24] M. Martin, A. Afshari, P.R. Armstrong, L.K. Norford, Estimation of urban temperature and humidity using a lumped parameter model coupled with an EnergyPlus model, Energy and Buildings, 96 (2015) 221-235.

[25] B. Bueno, L. Norford, G. Pigeon, R. Britter, A resistance-capacitance network model for the analysis of the interactions between the energy performance of buildings and the urban climate, Building and Environment, 54 (2012) 116-125.

[26] G. Pigeon, K. Zibouche, B. Bueno, J. Le Bras, V. Masson, Improving the capabilities of the Town Energy Balance model with up-to-date building energy simulation algorithms: an application to a set of representative buildings in Paris, Energy and Buildings, 76 (2014) 1-14.

[27] J. Allegrini, V. Dorer, J. Carmeliet, Coupled CFD, radiation and building energy model for studying heat fluxes in an urban environment with generic building configurations, Sustainable Cities and Society, 19 (Supplement C) (2015) 385-394.

[28] R. Evins, J. Allegrini, P. Moonen, Emulating site-specific wind flow information for use in building energy simulations, Building Simulation and Optimization (BSO 2014), London, UK, (2014).

[29] S. Gracik, M. Heidarinejad, J. Liu, J. Srebric, Effect of urban neighborhoods on the performance of building cooling systems, Building and Environment, 90 (2015) 15-29.

[30] Y.K. Yi, N. Feng, Dynamic integration between building energy simulation (BES) and computational fluid dynamics (CFD) simulation for building exterior surface, in: Building Simulation, Springer, 2013, pp. 297-308.

[31] H. Kim, J. Haw, T. Kim, S.-B. Leigh, APPLICATION OF COUPLED SIMULATION BETWEEN BES-CFD FOR NATURALLY VENTILATED RESIDENTIAL BUILDINGS, (213).

[32] R. Ramponi, A. Angelotti, B. Blocken, Energy saving potential of night ventilation: Sensitivity to pressure coefficients for different European climates, Applied Energy, 123 (2014) 185-195.

[33] R. Zhang, K.P. Lam, S.-C. Yao, Y. Zhang, Coupled EnergyPlus and computational fluid dynamics simulation for natural ventilation, Building and Environment, 68 (2013) 100-113.

[34] H.-N.S. Chin, M.J. Leach, G.A. Sugiyama, J.M. Leone Jr, H. Walker, J. Nasstrom, M.J. Brown, Evaluation of an urban canopy parameterization in a mesoscale model using VTMX and URBAN 2000 data, Monthly weather review, 133 (7) (2005) 2043-2068.

[35] J. Tanimoto, A. Hagishima, P. Chimklai, Development of an advanced computer tool, ausssm tool, for a coupling simulation with building thermal system and urban climatology, Building Simulation, IBPSA, Eindhoven, Netherlands, (2003). 
[36] J. Allegrini, J. Carmeliet, Coupled CFD and building energy simulations for studying the impacts of building height topology and buoyancy on local urban microclimates, Urban Climate, 21 (2017) 278-305. [37] A.A. Ragheb, I.I. El-Darwish, S. Ahmed, Microclimate and human comfort considerations in planning a historic urban quarter, International Journal of Sustainable Built Environment, 5 (1) (2016) 156-167.

[38] M. Shirzadi, M. Naghashzadegan, P.A. Mirzaei, Improving the CFD modelling of cross-ventilation in highly-packed urban areas, Sustainable Cities and Society, 37 (2018) 451-465.

[39] D. Costola, B. Blocken, J. Hensen, Overview of pressure coefficient data in building energy simulation and airflow network programs, Building and Environment, 44 (10) (2009) 2027-2036.

[40] N. Ikegaya, C. Hirose, A. Hagishima, J. Tanimoto, Effect of turbulent flow on wall pressure coefficients of block arrays within urban boundary layer, Building and Environment, 100 (2016) 28-39.

[41] P. Karava, T. Stathopoulos, A. Athienitis, Airflow assessment in cross-ventilated buildings with operable façade elements, Building and Environment, 46 (1) (2011) 266-279.

[42] M. Shirzadi, P.A. Mirzaei, M. Naghashzadegan, Development of an adaptive discharge coefficient to improve the accuracy of cross-ventilation airflow calculation in building energy simulation tools, Building and Environment, (2017).

[43] M. Mirsadeghi, D. Cóstola, B. Blocken, J.L. Hensen, Review of external convective heat transfer coefficient models in building energy simulation programs: implementation and uncertainty, Applied Thermal Engineering, 56 (1) (2013) 134-151.

[44] M. Shirzadi, P. Mirzaei, M. Naghashzadegan, On the cross ventilation for a generic building in unsheltered and sheltered conditions in: 16th International Conference on Sustainable Energy Technologies, Italy, 2017, pp. 1-10.

[45] M. Shirzadi, P.A. Mirzaei, M. Naghashzadegan, Y. Tominaga, Modelling Enhancement of Crossventilation in Sheltered Buildings using Stochastic Optimization International Journal of Heat and Mass Transfer, (2017).

[46] S.B. Pope, Turbulent flows, in, IOP Publishing, 2001.

[47] M. Shirzadi, P.A. Mirzaei, M. Naghashzadegan, Improvement of k-epsilon turbulence model for CFD simulation of atmospheric boundary layer around a high-rise building using stochastic optimization and Monte Carlo sampling technique, Journal of Wind Engineering and Industrial Aerodynamics, (2017).

[48] A.A. Razak, A. Hagishima, N. Ikegaya, J. Tanimoto, Analysis of airflow over building arrays for assessment of urban wind environment, Building and Environment, 59 (2013) 56-65.

[49] M. Schatzmann, COST 732 model evaluation case studies: approach and results, Meteorological Inst., 2010.

[50] W. Edeling, P. Cinnella, R.P. Dwight, H. Bijl, Bayesian estimates of parameter variability in the k- $\varepsilon$ turbulence model, Journal of Computational Physics, 258 (2014) 73-94.

[51] S. Guillas, N. Glover, L. Malki-Epshtein, Bayesian calibration of the constants of the $k-\varepsilon$ turbulence model for a CFD model of street canyon flow, Computer Methods in Applied Mechanics and Engineering, 279 (2014) 536-553.

[52] J. Schaefer, S. Hosder, T. West, C. Rumsey, J.-R. Carlson, W. Kleb, Uncertainty quantification of turbulence model closure coefficients for transonic wall-bounded flows, AIAA Journal, 55 (1) (2016) 195213.

[53] P. Koch, R.-J. Yang, L. Gu, Design for six sigma through robust optimization, Structural and Multidisciplinary Optimization, 26 (3-4) (2004) 235-248.

[54] R. Jin, W. Chen, A. Sudjianto, An efficient algorithm for constructing optimal design of computer experiments, Journal of Statistical Planning and Inference, 134 (1) (2005) 268-287.

[55] F. Campolongo, J. Cariboni, A. Saltelli, An effective screening design for sensitivity analysis of large models, Environmental modelling \& software, 22 (10) (2007) 1509-1518.

[56] A. CFX, Solver Theory Guide. Ansys, Inc., Canonsburg, PA, (2011). 
[57] M. Lokmanhekim, Procedure for determining heating and cooling loads for computerized energy calculations: Algorithms for building heat transfer subroutines, ASHRAE, 1971.

[58] N. Ito, Field experiment study on the convective heat transfer coefficient on exterior surface of a building, ASHRAE Trans.;(United States), 78 (1972).

[59] D. Loveday, A. Taki, Convective heat transfer coefficients at a plane surface on a full-scale building facade, International Journal of Heat and Mass Transfer, 39 (8) (1996) 1729-1742.

[60] Y. Liu, D.J. Harris, Full-scale measurements of convective coefficient on external surface of a lowrise building in sheltered conditions, Building and Environment, 42 (7) (2007) 2718-2736.

[61] D.S. Broomhead, D. Lowe, Radial basis functions, multi-variable functional interpolation and adaptive networks, in, DTIC Document, 1988.

[62] E.J. Kansa, Motivation for using radial basis functions to solve PDEs, RN, 64 (1) (1999) 1.

[63] P. Richards, S. Norris, Appropriate boundary conditions for computational wind engineering models revisited, Journal of Wind Engineering and Industrial Aerodynamics, 99 (4) (2011) 257-266.

[64] M. Kato, B. Launder, The modelling of turbulent flow around stationary and vibrating square cylinders, Turbulent Shear Flow, 1 (1993) 10.14. 11-10.14. 16.

[65] Y. Mori, K. Hishida, M. Maeda, Buoyancy effects on the wake behind a heated obstacle immersed in a turbulent boundary layer, International journal of heat and fluid flow, 16 (5) (1995) 405-416.

[66] B.E. Launder, D. Spalding, The numerical computation of turbulent flows, Computer methods in applied mechanics and engineering, 3 (2) (1974) 269-289.

[67] C.M. Rhie, W.L. Chow, Numerical study of the turbulent flow past an airfoil with trailing edge separation, AIAA Journal, 21 (11) (1983) 1525-1532.

[68] P.A. Mirzaei, J. Carmeliet, Dynamical computational fluid dynamics modeling of the stochastic wind for application of urban studies, Building and Environment, 70 (2013) 161-170.

[69] Y. Tominaga, A. Mochida, R. Yoshie, H. Kataoka, T. Nozu, M. Yoshikawa, T. Shirasawa, AlJ guidelines for practical applications of CFD to pedestrian wind environment around buildings, Journal of wind engineering and industrial aerodynamics, 96 (10) (2008) 1749-1761.

[70] Y. Tamura, T. Ohkuma, H. Kawai, Y. Uematsu, K. Kondo, Revision of AlJ Recommendations for wind loads on buildings, in: Structures 2004: Building on the Past, Securing the Future, 2004, pp. 1-10.

[71] Y. Tamura, Aerodynamic database for low-rise buildings, Global Center of Excellence Program, Tokyo Polytechnic University, Database, (2012).

[72] M. Swami, S. Chandra, Correlations for pressure distribution on buildings and calculation of naturalventilation airflow, ASHRAE transactions, 94 (3112) (1988) 243-266. 